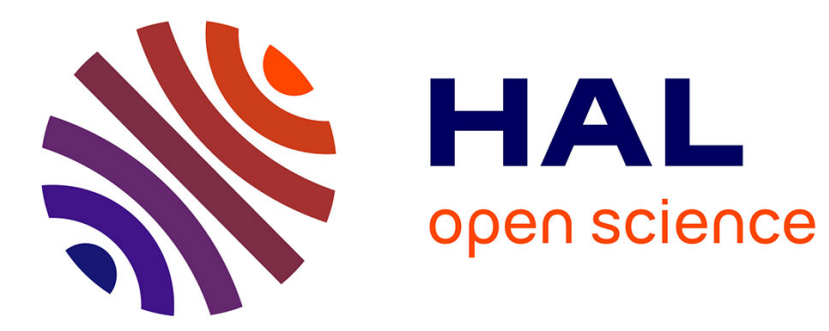

\title{
Insights on hydride formation over cerium-gallium mixed oxides: A mechanistic study for efficient $\mathrm{H} 2$ dissociation
} Julia Vecchietti, Miguel A. Baltanas, Christel Gervais, Sebastian E. Collins, Ginesa Blanco, Olivier Matz, Monica Calatayud, Adrian Bonivardi

\section{- To cite this version:}

Julia Vecchietti, Miguel A. Baltanas, Christel Gervais, Sebastian E. Collins, Ginesa Blanco, et al.. Insights on hydride formation over cerium-gallium mixed oxides: A mechanistic study for efficient $\mathrm{H} 2$ dissociation. Journal of Catalysis, 2017, 345, pp.258-269. 10.1016/j.jcat.2016.11.029 . hal-01518199

\author{
HAL Id: hal-01518199 \\ https://hal.science/hal-01518199
}

Submitted on 24 Apr 2020

HAL is a multi-disciplinary open access archive for the deposit and dissemination of scientific research documents, whether they are published or not. The documents may come from teaching and research institutions in France or abroad, or from public or private research centers.
L'archive ouverte pluridisciplinaire HAL, est destinée au dépôt et à la diffusion de documents scientifiques de niveau recherche, publiés ou non, émanant des établissements d'enseignement et de recherche français ou étrangers, des laboratoires publics ou privés.

\section{(c)(1)}

Distributed under a Creative Commons Attribution| 4.0 International License 


\title{
Insights on hydride formation over cerium-gallium mixed oxides: A mechanistic study for efficient $\mathrm{H}_{2}$ dissociation ${ }^{\text {th }}$
}

\author{
Julia Vecchietti a , Miguel A. Baltanás ${ }^{a}$, Christel Gervais ${ }^{\text {b,e }}$, Sebastián E. Collins ${ }^{\text {a,f }}$, Ginesa Blanco ${ }^{c}$, \\ Olivier Matz $^{\mathrm{d}}$, Monica Calatayud ${ }^{\mathrm{d}, \mathrm{e}, *}$, Adrian Bonivardi ${ }^{\mathrm{a}, \mathrm{f}, *}$ \\ a Instituto de Desarrollo Tecnológico para la Industria Química (INTEC) UNL-CONICET, Güemes 3450, 3000 Santa Fe, Argentina \\ ${ }^{\mathrm{b}}$ Sorbonne Universités, UPMC Univ Paris 06, CNRS, Chimie de la Matière Condensée de Paris, CC 174, 4 place Jussieu, F-75252 Paris Cedex 05, France

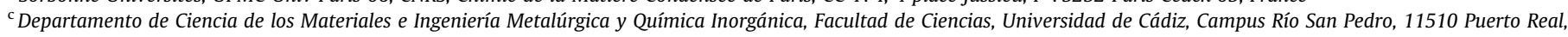 \\ Cádiz, Spain \\ d Sorbonne Universités, UPMC Univ Paris 06, CNRS, Laboratoire de Chimie Théorique, CC 137, 4 place Jussieu, F-75252 Paris Cedex 05, France \\ e Institut Universitaire de France, France \\ ${ }^{\mathrm{f}}$ Facultad de Ingeniería Química, UNL, Santiago del Estero 2829, 3000 Santa Fe, Argentina
}

A four-step reaction mechanism is proposed for the $\mathrm{H}_{2}$ dissociation over pure ceria and galliumpromoted mixed oxide materials, in a combined experimental and computational investigation. Two samples of cerium-gallium mixed oxides with $\mathrm{Ce} / \mathrm{Ga}$ atomic ratios equal to $90 / 10$ and 80/20 were studied by time-resolved diffuse reflectance infrared spectroscopy under $\mathrm{H}_{2}\left(\mathrm{D}_{2}\right)$ flow at isothermal condition in the range of 523-623 K. X-ray photoelectron spectrometry allowed to conclude that only $\mathrm{Ce}^{4+}$ is reduced to $\mathrm{Ce}^{3+}\left(\mathrm{Ga}^{3+}\right.$ is not reduced), in agreement with density functional theory (DFT) results. The time evolution profiles of gallium hydride $(\mathrm{Ga}-\mathrm{H})$ species, hydroxyl groups $(\mathrm{OH})$ and $\mathrm{Ce}^{3+}$ infrared signals were analyzed and kinetic rate parameters for each step were obtained by mathematical modeling. The values for activation energies were in agreement with those calculated by DFT, for the different elementary pathways. A small activation energy ( $\sim 4 \mathrm{kcal} / \mathrm{mol}$ ) was found for $\mathrm{H}_{2}$ dissociation found on $\mathrm{Ga} \cdots \mathrm{O}-\mathrm{Ce}$ sites assuming that the heterolytic cleavage of the $\mathrm{H}-\mathrm{H}$ bond is the rate determining step. On pure ceria, the experimental activation energy is $\sim 23 \mathrm{kcal} / \mathrm{mol}$, showing that the addition of $\mathrm{Ga}^{3+}$ cations boosts the splitting of $\mathrm{H}_{2}$. Interestingly, the reduction step of pure $\mathrm{CeO}_{2}$ surface domains seems to proceed via a $\mathrm{CeH} / \mathrm{OH}$ pair intermediate, according to DFT calculations. Moreover, ${ }^{71} \mathrm{Ga}$ NMR experiments indicate the possible presence of gallia nanodomains. It is proposed that the generation of $\mathrm{Ga} \cdots \mathrm{O}-\mathrm{Ce}$ sites in the perimeter of such surface gallia nanodomains is responsible for the enhanced reactivity of the mixed materials. The key role of this new type of sites to improve the efficiency of relevant catalytic reactions such as selective alkyne hydrogenation and light alkane dehydrogenation is then analyzed.

\section{Introduction}

Metal surface hydrides have been used (by Michael Faraday) since the earliest beginnings of heterogeneous catalysis [1]. Nowadays, hydrides, both on metallic or oxide surfaces, are involved in

\footnotetext{
This contribution is part of the virtual issue "30 years of the International Conferences on Theoretical Aspects of Catalysis (ICTAC)".

* Corresponding authors at: Sorbonne Universités, UPMC Univ Paris 06, CNRS, Laboratoire de Chimie Théorique, CC 137, 4 place Jussieu, F-75252 Paris cedex 05, France (M. Calatayud). Instituto de Desarrollo Tecnológico para la Industria Química (INTEC) UNL-CONICET, Güemes 3450, 3000 Santa Fe, Argentina (A. Bonivardi).

E-mail addresses: calatayu@lct.jussieu.fr (M. Calatayud), abonivar@santafeconicet.gov.ar (A. Bonivardi).
}

several important catalytic processes such as reforming, hydrogenation or dehydrogenation reactions.

Hydrides on metals are more widely employed and better understood than on oxides, where more complex surface sites are usually present [2]. For example, Ga-H on gallium-modified zeolites, or gallium-supported on different oxides (i.e., $\mathrm{SiO}_{2}, \mathrm{ZrO}_{2}$, $\mathrm{TiO}_{2}, \mathrm{Al}_{2} \mathrm{O}_{3}$ ), has been shown to have a key role in alkane dehydrogenation reactions for the production of aromatic compounds or olefins. However, the exact nature of the active site(s) in these reactions is still under debate $[3,4]$.

Gallium-based catalysts have also been used for the selective hydrogenation of $\mathrm{CO}_{2}$ to methanol [5-7], where the gallia surface is responsible for the formation of carbonate species. These species can be further hydrogenated to formate, methylenbisoxide and 
methoxy groups and the $\mathrm{Ga}_{2} \mathrm{O}_{3}$ surface is simultaneously able to dissociate $\mathrm{H}_{2}$ [8]. More recently, some of us have proved that doping ceria with gallium increased substantially the activity of pure $\mathrm{CeO}_{2}$ for selective semi-hydrogenation of alkynes, and this behavior was ascribed to the enhancement of molecular-hydrogen activation on these gallium-promoted catalysts [9].

Kinetic analyses of reduction by $\mathrm{H}_{2}$ of pure ceria have been previously reported $[10,11]$. El Fallah et al. developed a kinetic model by considering the surface and bulk reduction under stationary conditions and found that $\mathrm{H}_{2}$ dissociation is the rate determining step in the surface process, followed by a much slower anionic bulk diffusion step [10]. On low and high surface area $\mathrm{CeO}_{2}$, Giordano et al. studied the $\mathrm{H}_{2}$ consumption in the range of $500-1400 \mathrm{~K}$ employing modified temperature-programmed reduction (TPR) experiments. They proposed a simple kinetic model, which was able to describe the unimodal and (qualitatively) bimodal shape TPR profiles of their samples [11]. Although in these works the reduction was followed by non-surface sensitive techniques, such as X-ray photoabsorption (XAS) [10], thermogravimetry (TGA) [10], and TPR [11], those studies confirmed that under $\sim 650 \mathrm{~K}$ oxygen diffusion (that is, bulk ceria reduction), is negligible in pure $\mathrm{CeO}_{2}$.

Likewise, the kinetics of hydrogen activation on reduced ceriazirconia was studied by Schimming et al., concluding that two types of sites dominate the $\mathrm{H}_{2}-\mathrm{D}_{2}$ exchange reaction on this mixed oxide, one below and the other over $\sim 550 \mathrm{~K}$ [12], pointing out the role of oxygen vacancies and the edges of the ceria-zirconia crystallites, respectively.

In particular, cerium-gallium mixed oxides, formerly used by some of us as a catalyst support for the study of water gas shift (WGS) reaction [13], showed a noticeable enhancement of the ceria reducibility, which was attributed to a decrease of the activation barrier for $\mathrm{H}-\mathrm{H}$ cleavage [14]. The improvement of the redox properties of the gallium-doped ceria supports with a variable atomic ratio Ga-to-Ce was thoroughly verified by a combination of experimental techniques such as ultimate oxygen storage capacity [9,14], TPR by $\mathrm{H}_{2}$ and $\mathrm{CO}[9,13]$, time-resolved X-ray diffraction [14] and in situ X-ray absorption spectrometry (XAS) [14]. Also the formation of cerium-gallium mixed oxides was suggested from the results of bulk characterization by means of X-ray diffraction, high-resolution electron microscopy (HRTEM) by digital diffraction patterns (DDP) and annular dark-field scanning mode (HAADFSTEM), and energy-dispersive X-ray spectrometry (EDS) mapping $[9,13,15]$.

Additionally, non-isothermal and isothermal reduction by $\mathrm{H}_{2}$ using infrared spectroscopy was mainly used to find out the origin of the superior reducibility. Monitoring the behavior of the $\mathrm{Ce}-\mathrm{Ga}$ mixed oxides under $\mathrm{H}_{2}$ flow was possible due to the characteristic IR signals of $\mathrm{Ga}-\mathrm{H}$ and $\mathrm{Ce}^{3+}$, located at $\sim 1960$ [8,16,17] and $2130 \mathrm{~cm}^{-1}$ [18-21], respectively. The evolution of these infrared bands allowed to suggest two global steps for the initial stages of the surface reduction, involving the key participation of $\mathrm{Ga}^{3+}-\mathrm{O}$ surface sites, where $\mathrm{H}_{2}$ was proposed to be heterolytically dissociated to give $\mathrm{Ga}-\mathrm{H}$ and hydroxyl species, which are -in turn-, responsible for the facile reduction of $\mathrm{Ce}^{4+}$ to $\mathrm{Ce}^{3+}[14]$.

The gallium-cerium mixed oxides were modeled by density functional theory (DFT) by some of us confirming their higher bulk reducibility [22] as well as the role of interface oxygen sites in reactivity toward the WGS reaction [13]. The formation of surface gallium hydride species is a key step in the mechanism of $\mathrm{H}_{2}$ dissociation since they allow decreasing considerably the activation barrier, as in the case of alkyne semi-hydrogenation [14]. The formation of cerium hydrides has been recently reported in theoretical works as key intermediates for the $\mathrm{H}_{2}$ dissociation on pure ceria, with activation barriers of $\sim 1 \mathrm{eV}$ to form the hydroxylated surface [23-25].
In the present work X-ray photoelectron spectrometry (XPS), solid-state nuclear magnetic resonance (NMR) and time-resolved diffuse reflectance Fourier Transform infrared spectroscopy (DRIFTS) were used to postulate a detailed mechanistic model for the $\mathrm{H}_{2}$ surface reduction of these $\mathrm{Ce}-\mathrm{Ga}$ mixed oxides in the 523-623 $\mathrm{K}$ temperature range. To better understand the role of $\mathrm{Ga}-\mathrm{H}$ species and to validate the proposed mechanism, density functional theory (DFT) simulations were performed providing a coherent mechanistic scenario for the dissociation of $\mathrm{H}_{2}$ on mixed cerium-gallium oxides. The impact of the findings on heterogeneous catalytic processes is also analyzed.

\section{Experimental}

\subsection{Synthesis of materials}

Two cerium-gallium mixed oxides with nominal Ga: $(\mathrm{Ce}+\mathrm{Ga})$ atomic ratios equal to $10 \%$ and $20 \%$ (hereafter, Ce90Ga10 and Ce80Ga20, respectively) were prepared, from high purity grade nitrate salts (Sigma-Aldrich, 99.99\% Ce and 99.999\% Ga). Details of the synthesis method have been previously reported $[13,14,26]$. Briefly, the mixed cerium-gallium oxides were prepared by precipitation in ammonia solution ( $\mathrm{pH} 8.5$ ) of the respective nitrates dissolved in water, followed by washing, drying and calcining at $723 \mathrm{~K}$. The specific surface of the calcined oxides, measured by the BET method, was 108 and $91 \mathrm{~m}^{2} / \mathrm{g}$ for Ce90Ga10 and Ce80Ga20, respectively. After reduction under $\mathrm{H}_{2}$ at $623 \mathrm{~K}$ $(2 \mathrm{~h})$ the BET surface areas for both materials remained unchanged (109 and $86 \mathrm{~m}^{2} / \mathrm{g}$, respectively). That is, in what follows sintering of either oxide after $\mathrm{H}_{2}$ reduction can be ruled out. Some details of further characterization by TPR, XRD, HRTEM, OSC, XAS and EDS of these mixed oxides have been formerly published $[9,13,14]$.

\subsection{Isothermal reduction studies followed by time-resolved DRIFTS}

The isothermal reduction with $\mathrm{H}_{2}\left(30 \mathrm{~cm}^{3} / \mathrm{min}\right)$ was studied at 523, 543 and $623 \mathrm{~K}$ (for Ce90Ga10) and 523, 573 and $623 \mathrm{~K}$ (for Ce80Ga20) by means of step experiments, using aliquots $(50 \mathrm{mg} /$ ea.) of the oxidized materials. A Harrick high-temperature cell (model HCV-DRP, Praying Mantis) with ZnSe windows, located in the sample compartment of a Nicolet 8700 FTIR spectrometer furnished with a $\mathrm{Hg}-\mathrm{Cd}-\mathrm{Te}$ detector was used.

The experimental protocol was as follows: (1) heating under $\mathrm{H}_{2}$ flow from 298 to $623 \mathrm{~K}(10 \mathrm{~K} / \mathrm{min})$; (2) isothermal treatment at $623 \mathrm{~K}$ with a $\mathrm{H}_{2}-\mathrm{He}-\mathrm{H}_{2}-\mathrm{He}-\mathrm{O}_{2}-\mathrm{He}$ gas sequence (10 min under the flow of each gas); (3) isothermal reduction at $623 \mathrm{~K}$ under $\mathrm{H}_{2}$ flow (first step FTIR measurement, under constant data acquisition, during $20 \mathrm{~min}$ ); (4) oxidation by $\mathrm{O}_{2}$ at $623 \mathrm{~K}, 15 \mathrm{~min}$; (5) purging of the cell with $\mathrm{He}$, at $623 \mathrm{~K}$, for $10 \mathrm{~min}$; (6) cooling under He to 543 (for Ce90Ga10) or $573 \mathrm{~K}$ (for Ce80Ga20), respectively; (7) isothermal reduction experiment under $\mathrm{H}_{2}$ flow at the indicated temperatures for each catalyst (second step FTIR measurement, for $20 \mathrm{~min}$ ); (8) purging of the cell with $\mathrm{He}$, for $10 \mathrm{~min}$; and (9) $\mathrm{H}_{2}$ treatment for $10 \mathrm{~min}$. Next, each sample was heated under He to $623 \mathrm{~K}$ and steps 4-9 were repeated, but this time the reduction temperature was $523 \mathrm{~K}$ (steps 6-9) for both materials. Gas flow was equal to $30 \mathrm{~cm}^{3} / \mathrm{min}$ in either case.

The isothermal reduction experiments over the pre-oxidized samples were repeated at 523 and $623 \mathrm{~K}$, but this time $\mathrm{D}_{2}$ was used as the reducing agent.

The DRIFT cell behaves as a continuous stirred tank reactor (CSTR) with a residence time equal to $30 \mathrm{~s}$ for the volumetric flow employed in these step experiments, which allowed reproducible IR results. The temperature of the sample into the cup of the DRIFT cell was calibrated under gas flow by using a thermocouple 
inserted into the sample holder loaded with $\mathrm{CeO}_{2}$. Time-resolved IR spectra were taken consecutively with an average of 25 scans (acquisition time $=5 \mathrm{~s}$ ) and a resolution equal to $4 \mathrm{~cm}^{-1}$.

Ultra high purity $\mathrm{He}, \mathrm{O}_{2}$ and $\mathrm{H}_{2}$ (99.999\%), together with research grade $D_{2}(99.7 \%)$ supplied by Air Liquide were used.

\subsection{XPS}

X-ray Photoelectron Spectroscopy studies were performed in a Kratos Axis Ultra ${ }^{\mathrm{DLD}}$ instrument, by using monochromatized Al $\mathrm{K} \alpha$ radiation $(1486.6 \mathrm{eV})$. The spectrometer was operated in the Constant Analyzer Energy (CAE) mode, with a selected pass energy of $20 \mathrm{eV}$. Surface charging effects were compensated by using the Kratos coaxial neutralization system. The Binding Energy (BE) scale was calibrated with respect to the highest BE peak for Ce 3d core level ( $\mathrm{u}^{\prime \prime \prime}$ peak) at $917.0 \mathrm{eV}$ [27].

Surface composition calculations were obtained by using the Ga $2 \mathrm{p}_{3 / 2}$ and Ce $3 \mathrm{~d}$ signals, with the aid of XPSMultiQuant v. 7.0092 program [28], and surface contamination was corrected by using the method proposed in reference [29]. The surface oxidation states were checked by studying the Ce $3 d$, Ga $2 p_{3 / 2}$ and $\mathrm{Ga} 3 \mathrm{~d}_{5 / 2}$ signals, and the degree of cerium reduction was obtained by lineal combination of two reference spectra corresponding to $\mathrm{CeO}_{2}$ and $\mathrm{Ce}_{2} \mathrm{O}_{3}$.

Samples were pressed as self-supported wafers and submitted to a cleaning oxidizing treatment, at $523 \mathrm{~K}$, under flowing $\mathrm{O}_{2}(5 \%) / \mathrm{He}$, followed by successive reduction under flowing $\mathrm{H}_{2}(5 \%) / \mathrm{Ar}$ at 473,573 and $773 \mathrm{~K}(20 \mathrm{~min}$ each), in a reaction cell coupled to the spectrometer. This cell allows a clean transfer of the sample to the ultra-high vacuum chamber.

Spectral processing was performed with the CasaXPS software, version 2.3.17dev6.3a from Neal Fairley, Casa Software Ltd.

\subsection{Solid-state NMR}

${ }^{71} \mathrm{Ga}$ NMR experiments were performed on a $700 \mathrm{MHz}$ AVANCE III Bruker spectrometer operating at $213.47 \mathrm{MHz}$, using a $3.2 \mathrm{~mm}$ Bruker probe spinning at $22 \mathrm{kHz}$. A spin-echo $\theta-\tau-2 \theta$ pulse sequence with $\theta=90^{\circ}$ was used with a recycle delay of $2 \mathrm{~s}$. The $\tau$ delay was synchronized with the spinning frequency. Chemical shifts were referenced to $\mathrm{Ga}\left(\mathrm{NO}_{3}\right)_{3}$. Simulations of the NMR spectra were performed by using the DMFit software [30].

\subsection{DFT}

The Perdew-Burke-Ernerzhof (PBE) functional [31] was used as implemented in the VASP code 5.3.5 [32]. The valence electrons were treated explicitly with plane waves of energy below $282 \mathrm{eV}$, the core electrons were replaced by projector augmented wave (PAW) pseudopotentials [33] (Ce: $\mathrm{s}^{2} \mathrm{~d}^{1} \mathrm{f}^{1}, \mathrm{Ga}: \mathrm{d}^{10} \mathrm{~s}^{2} \mathrm{p}^{1}, \mathrm{O}: \mathrm{s}^{2} \mathrm{p}^{4}, \mathrm{H}$ : $\mathrm{s}^{1}$ ). This setting has proven to be well adapted for the ceria-gallia systems [9]. All calculations were spin-polarized, and the Hubbard $U$-like term describing the on-site Coulomb interactions was included in order to describe the Ce $4 f$ states $(U-J=5 \mathrm{eV}$ ) [34].

The mixed ceria-gallia system was modeled by two slabs. First, a slab of composition $\mathrm{Ce}_{35} \mathrm{GaO}_{72} \mathrm{H}$ where the $\mathrm{Ga}$ : $(\mathrm{Ce}+\mathrm{Ga})$ ratio is $2.77 \%$ for the whole model and $11.11 \%$ for the surface; it is built from a $3 \times 3$ (111)-terminated fluorite containing four $\mathrm{CeO}_{2}$ layers as displayed in Fig. 1. In this model the ions are in their highest oxidation states: $\mathrm{Ce}^{4+}, \mathrm{Ga}^{3+}, \mathrm{O}^{2-}$ and $\mathrm{H}^{+}$, and represent an isolated gallium. Second, a slab of composition $\mathrm{Ce}_{56} \mathrm{Ga}_{8} \mathrm{O}_{124}$ where the $\mathrm{Ga}$ :(Ce $+\mathrm{Ga}$ ) ratio is $12.5 \%$ for the whole model and $43.75 \%$ for the surface. It is built from a $4 \times 4(111)$-terminated fluorite containing four $\mathrm{CeO}_{2}$ layers, where $8 \mathrm{CeO}_{2}$ units are replaced by $4 \mathrm{Ga}_{2} \mathrm{O}_{3}$ units ( $7 \mathrm{Ga}$ in the top layer and $1 \mathrm{Ga}$ in the second layer), to represent a gallia cluster embedded in ceria (see Fig. S2, coordinates are

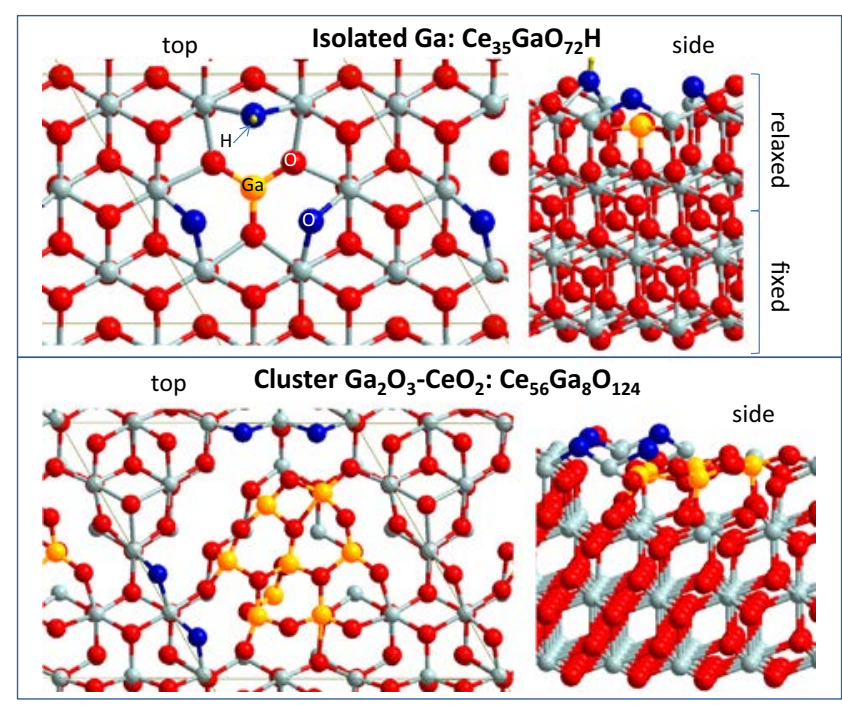

Fig. 1. Selected views of the cells used as model for the mixed ceria-gallia catalysts with isolated (top) and cluster (bottom) gallia sites. The oxygen atoms in blue are the topmost atoms, in the close vicinity of gallium (labelled Ga...O in Scheme 1); the gallium centers remain embedded in the ceria matrix.

given in Supporting Information). The structures are first fully optimized (convergence $10^{-4} \mathrm{eV}$ for the electronic loop, $10^{-3} \mathrm{eV}$ for the ionic loop) for the adsorbates and the top half layers; the bottom layers are frozen. The Brillouin zone is sampled with $k$-points distant $\sim 0.05 \AA^{-1}$. The vibrational frequencies of GaH are obtained by finite differences (step $0.02 \AA$ ) with only the GaH atoms allowed to move. Only the gamma point is considered in the Brillouin zone for the frequency calculations. The Nudged Elastic Band method [35] was used to locate transition state structures; a frequency analysis to confirm the nature of the saddle point was carried out.

\section{Results and discussion}

\subsection{Surface composition and reduction by XPS}

The surface gallium composition of the samples, defined as the $\mathrm{Ga}:(\mathrm{Ce}+\mathrm{Ga})$ atomic ratio, is shown in Table 1 . Regardless of the oxidizing or reducing treatment, the atomic composition was close to the nominal value, that is $10 \%$ and $20 \%$ for Ce90Ga10 and Ce80Ga20, respectively. The observed increase of this value for the Ce80Ga20 after the highest temperature of reduction and oxidation (to $\sim 25 \%$ ) might be an indication of $\mathrm{Ga}_{2} \mathrm{O}_{3}$ surface segregation or cluster formation induced by some preexisting nanodomains of gallia.

The oxidation state of surface gallium cations was $3+$ even after reducing the Ce80Ga20 at $773 \mathrm{~K}$ for $20 \mathrm{~min}$ in pure $\mathrm{H}_{2}$, since the $\mathrm{BE}$ Ga $2 \mathrm{p}_{3 / 2}$ and $3 \mathrm{~d}_{5 / 2}$ signal values were approx. 1117.8 and $20 \mathrm{eV}$, respectively, which is close to the reference values of 1117.8 [35] and $20.15 \mathrm{eV}$ [36]. The amount of $\mathrm{Ce}^{3+}$ increased with the reduction temperature, as expected (Table 1 ), and indicates that the reduction of the surface is related only to the change of $\mathrm{Ce}^{4+}$ to $\mathrm{Ce}^{3+}$ states. The oxidation states for the cerium and gallium surface cations are similar to those reported using bulk techniques in a previous work by some of us [14].

\subsection{Environment of gallium cations in the ceria matrix by NMR}

The ${ }^{71} \mathrm{Ga}$ MAS NMR spectrum of Ce80Ga20 is shown in Fig. 2 as well as those of the $\beta$ - and $\gamma-\mathrm{Ga}_{2} \mathrm{O}_{3}$ polymorphs, for comparison purposes. The $\beta$-gallia spectrum was simulated with two signals $\left(\delta_{\text {iso }}=40 \mathrm{ppm}, C_{\mathrm{Q}}=8.3 \mathrm{MHz}, \eta=0.1\right.$ and $\delta_{\text {iso }}=200 \mathrm{ppm}, C_{\mathrm{Q}}=11-$ 
Table 1

Atomic surface composition and binding energy values of Ga signals determined by XPS after different pretreatments.

\begin{tabular}{|c|c|c|c|c|c|}
\hline Sample & Treatment & $\mathrm{Ce}^{3+}(\%)$ & $\mathrm{Ga}:(\mathrm{Ce}+\mathrm{Ga})$ atomic surface ratio $(\%)$ & $\mathrm{BE} \mathrm{Ga} 2 \mathrm{p}_{3 / 2}(\mathrm{eV})$ & BE Ga $3 d_{5 / 2}(\mathrm{eV})$ \\
\hline Ce90Ga10 & $\mathrm{O}_{2}, 523 \mathrm{~K}$ & 0 & 10 & 1118.0 & - \\
\hline \multirow{5}{*}{ Ce80Ga20 } & $\mathrm{O}_{2}, 523 \mathrm{~K}$ & 0 & 19 & 1117.8 & 19.9 \\
\hline & $\mathrm{H}_{2}, 473 \mathrm{~K}$ & 0 & 19 & 1117.8 & 19.9 \\
\hline & $\mathrm{H}_{2}, 573 \mathrm{~K}$ & 14 & 19 & 1117.9 & 20.0 \\
\hline & $\mathrm{H}_{2}, 773 \mathrm{~K}$ & 22 & 24 & 1117.9 & 19.7 \\
\hline & $\mathrm{O}_{2}, 523 \mathrm{~K}$ & 0 & 26 & 1117.9 & 20.0 \\
\hline
\end{tabular}

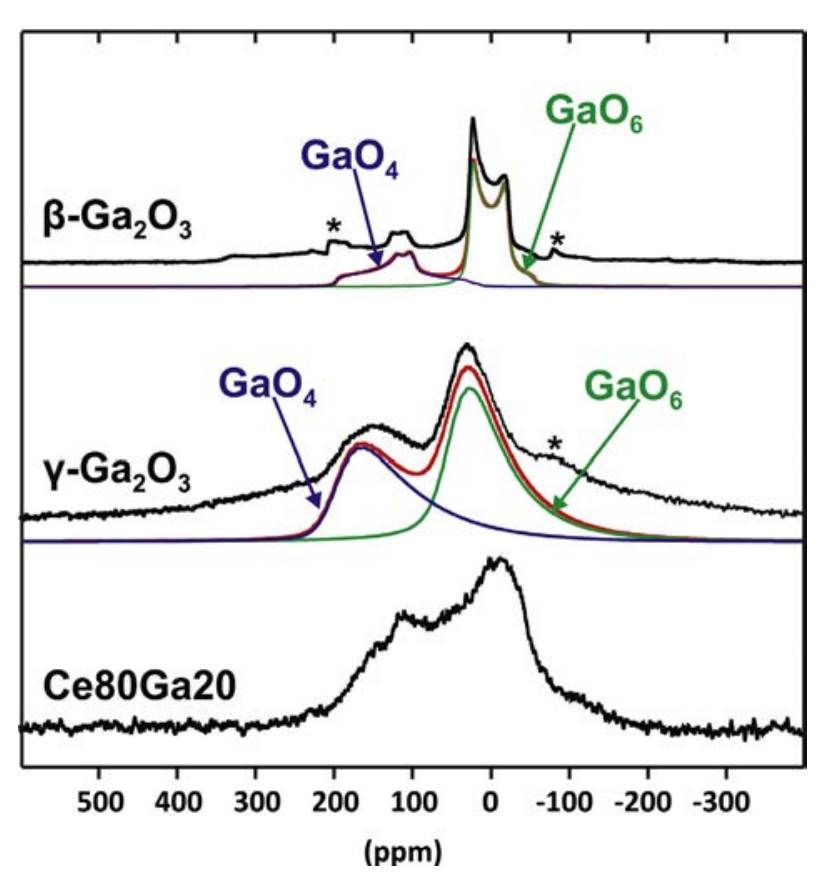

Fig. 2. Experimental and simulated ${ }^{71} \mathrm{Ga}$ MAS NMR spectra $\left(B_{0}=16.3 \mathrm{~T}\right.$, MAS $22 \mathrm{kHz}$ ) of $\mathrm{Ce} 80 \mathrm{Ga} 20, \beta$ - and $\gamma-\mathrm{Ga}_{2} \mathrm{O}_{3}$ polymorphs (asterisks indicate spinning sidebands).

$\mathrm{MHz}, \eta=0.8$ ) corresponding to $\mathrm{Ga}^{\mathrm{VI}}$ and $\mathrm{Ga}^{\mathrm{IV}}$ (that is, in octahedral and tetrahedral environments, respectively), in agreement with previously published results [37].

Ce80Ga20 exhibits two asymmetric lineshapes which are characteristic of a distribution of chemical shifts and quadrupolar parameters as the ones observed for the $\mathrm{Ga}^{\mathrm{VI}}$ and $\mathrm{Ga}^{\mathrm{IV}}$ sites in $\gamma$ $\mathrm{Ga}_{2} \mathrm{O}_{3}$ [38]. Yet, gallium-doped ceria should only exhibit $\mathrm{Ga}^{\mathrm{IV}}$ sites if they were isolated and homogeneously distributed [22]. Therefore, our NMR results suggest that even if the gallium cations were homogenously distributed in the $\mathrm{CeO}_{2}$ matrix at micrometric scale $[9,15]$, gallia aggregates of nanometric dispersion are also present in the material, which is in line with the evidence of some segregation or nucleation of gallium nanodomains suggested by the XPS results, after reduction of Ce80Ga20 at $773 \mathrm{~K}$.

\subsection{Proposed mechanism for the reaction of $\mathrm{H}_{2}$ over $\mathrm{Ce}-\mathrm{Ga}$ mixed oxides}

In order to simplify the reading of the coming sections, Scheme 1 shows a comprehensive, 4-step surface reaction mechanism that better represents the behavior of the $\mathrm{Ce}-\mathrm{Ga}$ mixed oxides upon exposure to hydrogen gas. Each of these reactions is mainly based on experimental IR evidence and supported or validated by theoretical calculations, which are presented and discussed in the following.
1)<smiles>[14CH3]O[14C@@H]([14CH2]O)O[14CH2]O[14CH2]O</smiles>

2)<smiles>O[14CH2][14CH2][14CH2][14CH2][14CH2][14CH2][14CH2][14CH2]O[14CH2][14CH2]O</smiles>

3)

$$
2 \mathrm{Ce}^{4+}+\mathrm{H}_{2}+\mathrm{O}^{2-} \longrightarrow 2 \mathrm{Ce}^{3+}+\mathrm{H}_{2} \mathrm{O}+\square
$$

4)

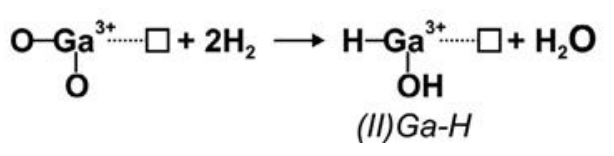

Scheme 1. 4-Step surface reduction mechanism proposed for ceria-gallia mixed oxides. The different surface $\mathrm{Ga}$ and $\mathrm{Ga}-\mathrm{H}$ species are identified in italics.

\subsection{Isothermal reaction experiments performed by time-resolved DRIFTS}

Time-resolved IR reaction experiments under isothermal conditions were performed over Ce90Ga10 and Ce80Ga20 samples, at three temperatures: 523, 543 or 573 (Ce90Ga10 or Ce80Ga20, respectively), and $673 \mathrm{~K}$. During these experiments, the characteristic IR signals of $\mathrm{Ga}-\mathrm{H}$ and the forbidden electronic transition ${ }^{2} \mathrm{~F}_{5 / 2} \rightarrow{ }^{2} \mathrm{~F}_{7 / 2}$ of $\mathrm{Ce}^{3+}$, located at $\sim 1960$ and $2130 \mathrm{~cm}^{-1}$, respectively, were systematically monitored as well as the $\mathrm{OH}$ stretching region, to account for the previously proposed reaction pathway of $\mathrm{H}_{2}$ on Ce-Ga mixed oxides [14].

\subsubsection{Evolution of the $\mathrm{Ga}-\mathrm{H}$ and $\mathrm{Ce}^{3+} \mathrm{IR}$ signals}

Figs. 3 and 4 show the IR spectra and color contour map in the $2300-1800 \mathrm{~cm}^{-1}$ wavenumber range as a function of time for Ce80Ga20 and Ce90Ga10, respectively, during the isothermal $\mathrm{H}_{2}$ reaction experiments at the three temperatures tested. The evolution with time of the integrated area of the $\mathrm{Ga}-\mathrm{H}$ and $\mathrm{Ce}^{3+}$ signals is shown in the bottom panels of Figs. 3 and 4 for both samples.

At $523 \mathrm{~K}$ on the Ce80Ga20 sample, the signal assigned to the stretching of the $\mathrm{Ga}^{3+}-\mathrm{H}$ species $\left(v_{\mathrm{GaH}}\right)$ at $1955 \mathrm{~cm}^{-1}$ increased almost instantly, reaching a maximum after $15 \mathrm{~s}$ of exposure to $\mathrm{H}_{2}$, and then began to decrease once the $\mathrm{Ce}^{3+}$ band arose (Fig. 3 top panel, $523 \mathrm{~K}$ ). This behavior is well illustrated in the color contour map, where it is observed that the signal at $1955 \mathrm{~cm}^{-1}$ reached an intense red color in just a few seconds and then, as soon as the signal at $2130 \mathrm{~cm}^{-1}$ began to be detected, it merged with the bluish (less signal intensity) colors during the first minute of 

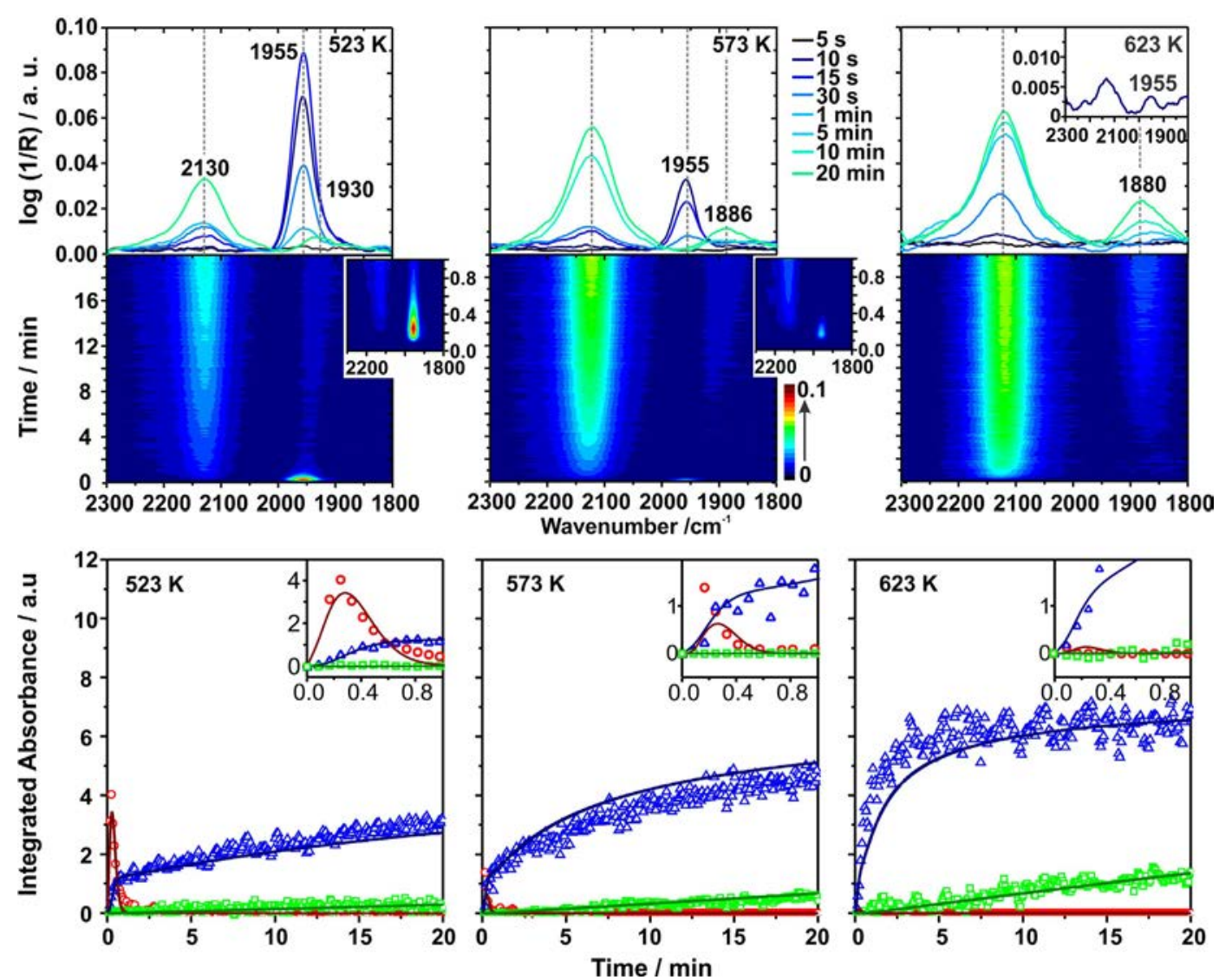

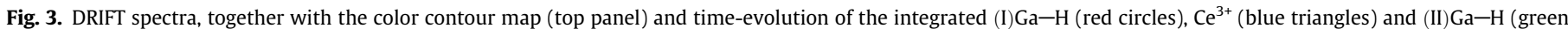

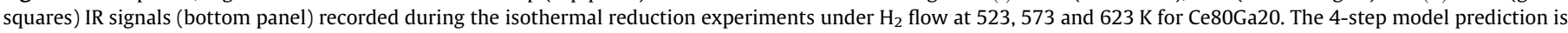
shown as solid lines in the bottom panel.

reduction (see inset in Fig. 3 color contour map, $523 \mathrm{~K}$ ). At the end of the experiment, a small $\mathrm{Ga}-\mathrm{H}$ signal located at $1930 \mathrm{~cm}^{-1}$ was also observed, and this shifting will be discussed later. Conversely, at $623 \mathrm{~K}$ a fast formation of the $\mathrm{Ce}^{3+}$ signal was appreciated, while a less intense band at $1955 \mathrm{~cm}^{-1}$ was detected after $10 \mathrm{~s}$ of exposure to $\mathrm{H}_{2}$ (see inset in Fig. 3 top panel, $623 \mathrm{~K}$ ).

These observations are congruent with the first two reactions of the mechanism presented in Scheme 1: Type I Ga sites [named (I) $\mathrm{Ga}$ ] react with gaseous $\mathrm{H}_{2}$ to form $\mathrm{Ga}^{3+}-\mathrm{H}$ [type $\mathrm{I} \mathrm{Ga}-\mathrm{H}$ species, hereby indicated as (I) $\mathrm{Ga}-\mathrm{H}$ ] and a hydroxyl species. Then, the (I) $\mathrm{Ga}-\mathrm{H}$ surface species produced in reaction (1) further reacts with a hydroxyl group in the vicinity of two adjacent $\mathrm{Ce}^{4+}$ cations to form water, two $\mathrm{Ce}^{3+}$ and a type II Ga site [labeled (II)Ga], as indicated in reaction (2). By assuming that the first reaction has lower activation energy than the second one, this allowed us to sustain the experimental observations of the evolution of $\mathrm{Ga}-\mathrm{H}$ and $\mathrm{Ce}^{3+}$ signals at 523 and $623 \mathrm{~K}$ [14]. That is, at the lowest reduction temperature the rate of reaction (2) is lower than that of reaction (1), while the opposite is true for the highest temperature. This hypothesis is sustained by the computational and kinetic modeling as well, as shown below.

The isothermal reduction experiment of Ce80Ga20 at the intermediate temperature, $573 \mathrm{~K}$, was quite revealing. At the beginning of the experiment $(t<2 \mathrm{~min})$ the behavior of the material was similar to that observed at $523 \mathrm{~K}$. However, in the latter case the intensity of the $\mathrm{Ga}^{3+}-\mathrm{H}$ signal was 3-fold higher ( 0.095 vs. 0.035 at 523 and $573 \mathrm{~K}$, respectively, see Fig. 3), and this can be again understood by the suggested different activation energies of reactions (1) and (2). In contrast, for longer times $(t>2 \mathrm{~min})$ a band at $\sim 1880 \mathrm{~cm}^{-1}$ started to be detected and grew gradually with time of exposure to $\mathrm{H}_{2}$, resembling the behavior of the same band observed a $623 \mathrm{~K}$. In the last case, it is clear that once the concentration of $\mathrm{Ce}^{3+}$ stabilized (after approx. $2 \mathrm{~min}$ ) the signal at $\sim 1880 \mathrm{~cm}^{-1}$ began to develop slowly.

These last results suggest quite convincingly that the low wavenumber signal at $\sim 1880 \mathrm{~cm}^{-1}$ cannot be assigned to the same species as the one observed at $1955 \mathrm{~cm}^{-1}$, as it was proposed before [14], but should be assigned instead to another Ga-H surface species: the type II $\mathrm{Ga}-\mathrm{H}$, labeled (II)Ga-H in Scheme 1. The origin of such species is suggested to occur after the reaction of $\mathrm{H}_{2}$ with (II)Ga sites (reaction (4) in Scheme 1). Therefore, the evolution of the (II) $\mathrm{Ga}-\mathrm{H}$ starts after the formation of $\mathrm{Ce}^{3+}$ and/ or (II)Ga sites by reaction (2), as it is shown in Figs. 3 and 4 (bottom panels).

Similar results were obtained for Ce90Ga10, although some differences were observed with respect to the sample with higher Ga loading (Fig. 4). First, at $523 \mathrm{~K}$ the maximum intensity of the (I) $\mathrm{Ga}-\mathrm{H}$ signal was 1.5 -fold higher on Ce90Ga10 than on Ce80Ga20 and, also, at $623 \mathrm{~K}$ a better detection of the same signal was observed on the lower gallium content sample. These results will be explained below using the insight provided by the mathematical modeling of the reduction mechanism. Second, although in both samples the asymptotic value of the surface $\mathrm{Ce}^{3+}$ concentration increased at higher temperature, the surface $\mathrm{Ce}^{3+}$ levels reached for Ce90Ga10 were always lower than on Ce80Ga20. This is in agreement with the decrease in the overall reduction of $\mathrm{Ce}-\mathrm{Ga}$ mixed oxides at lower gallium content observed using oxygen storage capacity (OSC) measurements at 573-773 K [14]. 

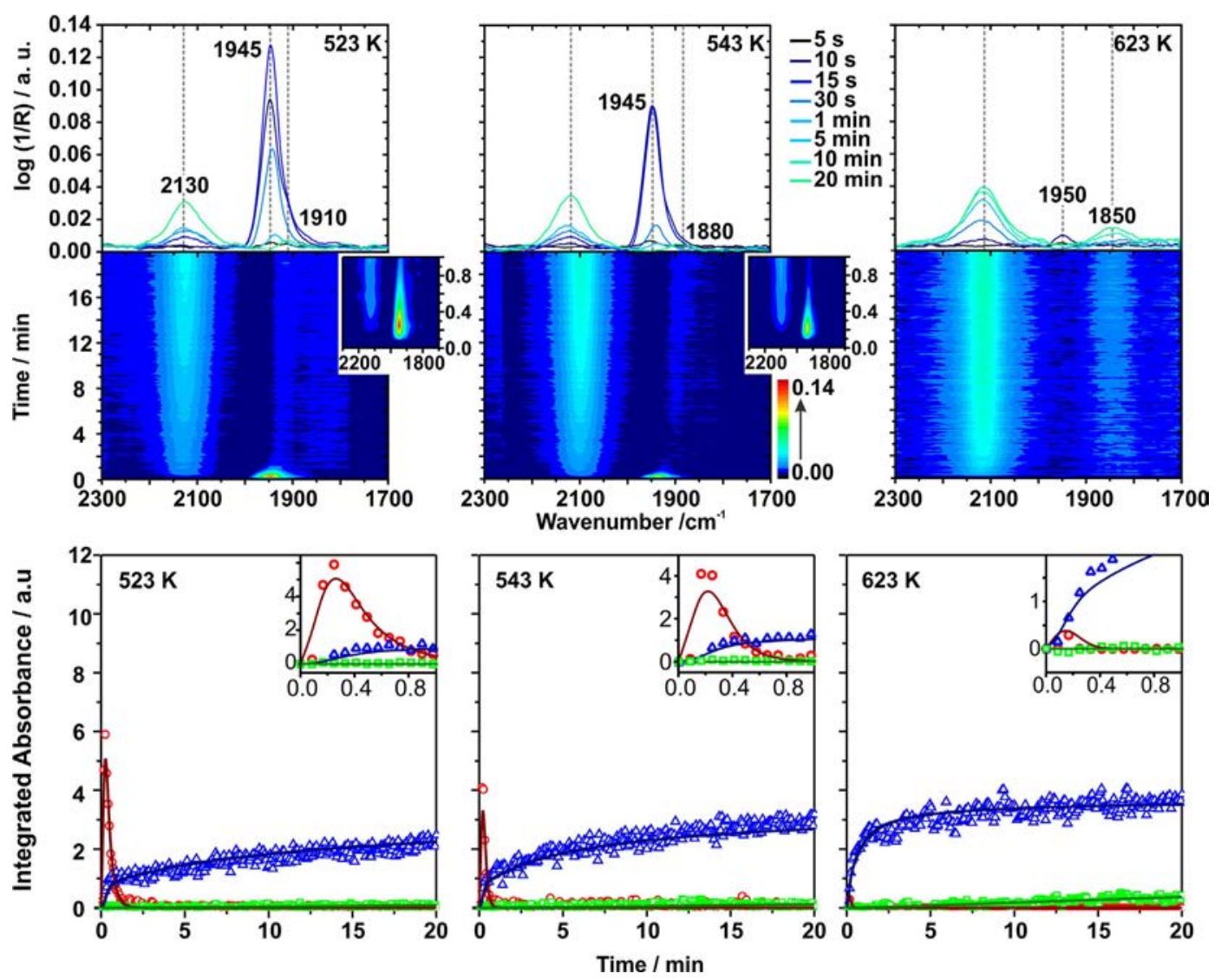

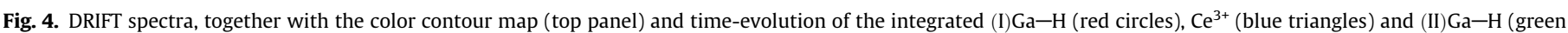

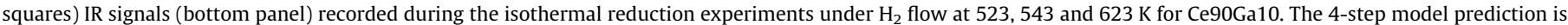
shown as solid lines in the bottom panel.

\subsubsection{Origin and assignment of the $\mathrm{Ga}-\mathrm{H}$ infrared signals}

The origin of the assignment of the band at $\sim 1960 \mathrm{~cm}^{-1}$ is based in previous works by some of us and other research groups $[8,16,17,39]$. Three aspects were formerly considered for the certain identification of this assignment. The first one refers to the wavenumber position of this signal as compared to the stretching mode arising from gallane-derived molecular systems (such as, chlorine-, phosphorous-, nitrogen- and alkyl-containing gallanes, and pure gallane) which is in the range of $1830-2050 \mathrm{~cm}^{-1}$ [39]. The next one is the band intensity with the surface gallium concentration for gallia-supported catalysts [39] and with the surface area of pure-gallia polymorphs [8]. Finally, the H-D exchange experiments on gallia-supported catalysts could be considered as a conclusive procedure for such assignment.

Then, to further ascertain the assignment of the (I) $\mathrm{Ga}-\mathrm{H}$ signal $\left(1955 \mathrm{~cm}^{-1}\right)$ and the singular evolution of this species under $\mathrm{H}_{2}$ flow, supplementary isothermal reduction experiments using $\mathrm{D}_{2}$ were carried out at 523 and $623 \mathrm{~K}$. Fig. S1 shows DRIFT spectra recorded during the isothermal reduction with $\mathrm{D}_{2}$ at $523 \mathrm{~K}$ for Ce80Ga20 and Ce90Ga10. It can be observed that the band of (I) $\mathrm{Ga}-\mathrm{D}$ appears at $\sim 1400 \mathrm{~cm}^{-1}$ under $\mathrm{D}_{2}$ flow, where the experimental ratio of the $v(\mathrm{Ga}-\mathrm{H}) / v(\mathrm{Ga}-\mathrm{D})$ frequencies is equal to 1.40 , in agreement with the theoretical ratio expected for the $\mathrm{H}-\mathrm{D}$ isotopic exchange of $\mathrm{Ga}-\mathrm{H}$ species $[v(\mathrm{Ga}-\mathrm{H}) / \mathrm{v}(\mathrm{Ga}-\mathrm{D})=$ $\left(\mu_{\mathrm{GaD}} / \mu_{\mathrm{GaH}}\right)^{1 / 2}$, where $\mu_{\mathrm{GaD}}$ and $\mu_{\mathrm{GaH}}$ are the reduced masses of $\mathrm{GaD}$ and $\mathrm{GaH}$, respectively].

The isothermal evolution of $\mathrm{Ga}-\mathrm{D}$ and $\mathrm{Ce}^{3+}$ signals as a function of time at $523 \mathrm{~K}$ for Ce80Ga20 and Ce90Ga10 (Fig. 5) is similar to the one observed under $\mathrm{H}_{2}$ flow (Figs. 3 and 4), confirming the particular behavior of these species under $\mathrm{H}_{2}$ flow.
The type II Ga-D band, expected at $\sim 1350 \mathrm{~cm}^{-1}$, was not detected at $623 \mathrm{~K}$ due to its low intensity and the strong, overlapping bands of the bulk carbonate species present in this spectral region. However, in an additional reduction experiment with $D_{2}$ at $723 \mathrm{~K}$, the intensity of a signal at $1350 \mathrm{~cm}^{-1}$ was high enough to be detected from the background and could then be assigned to (II) $\mathrm{Ga}-\mathrm{D}$ species $[\mathrm{v}(\mathrm{Ga}-\mathrm{H}) / \mathrm{v}(\mathrm{Ga}-\mathrm{D})=1.39]$.

The strong shift of the $\mathrm{Ga}-\mathrm{H}$ band from 1955 to $1880 \mathrm{~cm}^{-1}$ was formerly ascribed by some of us to either the fact that the chemical environment of the $\mathrm{Ga}-\mathrm{H}$ sites was modified by the presence of $\mathrm{Ce}^{3+}$, thus causing a change in the strength of the $\mathrm{Ga}-\mathrm{H}$ bond, or that $\mathrm{Ga}^{3+}$ was progressively reduced to a lower and stable oxidation state $[14,15]$. This last possibility can be excluded, at least at temperatures lower than $623 \mathrm{~K}$, because (i) XANES results were unable to show any reduction of the $\mathrm{Ga}^{3+}$ cations [14], and (ii) XPS measurements indicated that (near)surface $\mathrm{Ga}^{3+}$ reduction did not occur even after exposing Ce80Ga20 at $773 \mathrm{~K}$ to $\mathrm{H}_{2}$ during $30 \mathrm{~min}$, as shown above. Additionally, DFT calculations indicate the preferential reduction of $\mathrm{Ce}^{4+}$ rather than that of the $\mathrm{Ga}^{3+}$ cations. This is observed in the analysis of the spin density of systems in the presence of oxygen vacancies: the removal of one oxygen site leaves two electrons that are localized on two cerium sites neighboring the vacancy. The spin density isosurface plots for the case of one oxygen vacancy on the isolated-Ga model is displayed as Supplementary Information (Fig. S2), and shows the presence of the corresponding unpaired electrons in $\mathrm{Ce}^{3+}$ sites. A more detailed discussion about the types of oxygen vacancies is given in Supporting Information.

From the above results it seems reasonable to assume that oxygen vacancies next to $\mathrm{Ga}^{3+}$ cations should be responsible for the 


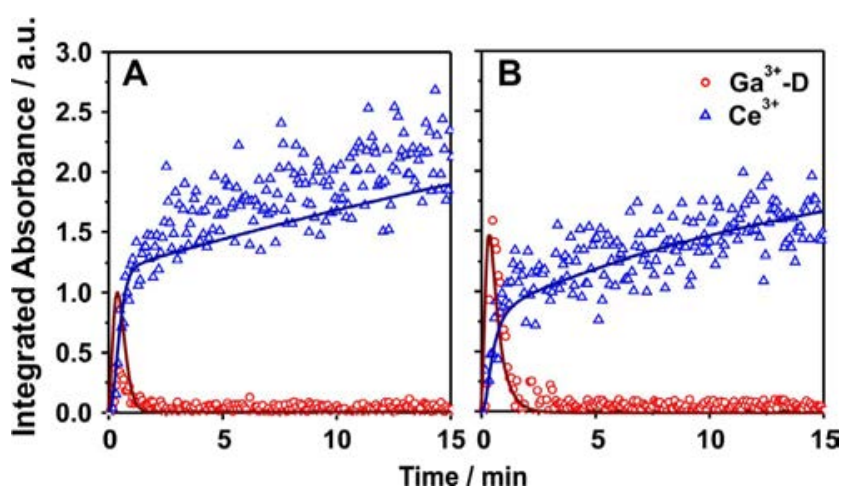

Fig. 5. Time evolution of the integrated (I) $\mathrm{Ga}-\mathrm{D}$ (red circles) and $\mathrm{Ce}^{3+}$ (blue triangles) DRIFT signals during the isothermal reduction under $\mathrm{D}_{2}$ flow at $523 \mathrm{~K}$ of Ce80Ga20 (A) and Ce90Ga10 (B). The solid lines represent the fitting of the proposed mechanism (Scheme 1), as detailed below and in Supplementary Information.

$\mathrm{Ga}-\mathrm{H}$ bond weakening, explaining the appearance of the bands at $1930-1910 \mathrm{~cm}^{-1}$ on both Ce-Ga mixed oxides at $523 \mathrm{~K}$ and those at $1880-1850 \mathrm{~cm}^{-1}$ at $623 \mathrm{~K}$ (Figs. 3 and 4 ).

In order to address this point we performed a computational analysis of the vibrational frequencies of several galliumcontaining systems. A detailed analysis can be found in Supplementary Information. First, a pure beta-gallia (100)-terminated slab [40] was computed in interaction with two $\mathrm{H}$ atoms. The most representative species observed are $\mathrm{Ga}-\mathrm{H}$ isolated sites that vibrate in the range $1850-1922 \mathrm{~cm}^{-1}$ (Fig. 6) whereas positioning $\mathrm{H}$ in the lattice or coupling it to a neighboring $\mathrm{OH}$ site decreases significantly the corresponding frequencies. Then, the mixed ceria-gallia model was also tested and the vibrational frequencies obtained were $1770-1850 \mathrm{~cm}^{-1}$ for the stoichiometric models and $1630-1800 \mathrm{~cm}^{-1}$ for the reduced ones (i.e., in the presence of oxygen vacancies). The vibrational frequencies correlate linearly with the $\mathrm{Ga}-\mathrm{H}$ distance, as shown in Fig. 6. Several trends are observed: low-coordinated (threefold) gallium cations exhibit higher vibrational frequencies than highly coordinated (fivefold) ones.

Also, the presence of oxygen vacancies clearly redshifts the vibrational frequencies in the case of the mixed material, whereas such trend does not appear so clear for pure gallia. This might be due to the different reduction mechanisms involved in each oxide: the mixed material is reduced by forming solely $\mathrm{Ce}^{3+}$ sites, whereas the pure gallia system creates F-centers that may stabilize $\mathrm{Ga}-\mathrm{H}$ pairs. This is the typical behavior of irreducible oxides where the reduction of cations to a lower oxidation state is not favorable
[41-43]. The range of observed $\mathrm{Ga}-\mathrm{H}$ frequencies might also indicate the presence of pure gallia domains. A detailed analysis of the formation of oxygen vacancies on pure gallia and their interaction with $\mathrm{H}_{2}$ is shown in Fig. $\mathrm{S} 5$, together with the corresponding calculated frequencies. Based on these results we conclude that in the absence of $\mathrm{Ce}-\mathrm{O}-\mathrm{Ce}$ or $\mathrm{Ga}$...O-Ce sites the $\mathrm{Ga}-\mathrm{H}$ species formed might involve oxygen vacancies in pure gallia regions.

\subsubsection{Evolution and assignment of $\mathrm{OH}$ signals}

It has been suggested previously that $\mathrm{H}_{2}$ adsorption over pure gallium oxide is a heterolytic process which leads to the formation of $\mathrm{Ga}-\mathrm{H}$ and a hydroxyl group $[8,17]$. Thus, to gain further information on the reaction pathways of $\mathrm{H}_{2}$ over $\mathrm{Ce}-\mathrm{Ga}$ mixed oxides an infrared analysis of the $\mathrm{OH}$ region is carried out, taken during the reduction with $\mathrm{H}_{2}$ at 523 and $623 \mathrm{~K}$ for Ce80Ga20 and displayed in Fig. 7.

At the beginning of the experiment, two broad bands at 3630 and $3680 \mathrm{~cm}^{-1}$ were detected. After exposing the material to $\mathrm{H}_{2}$ at $523 \mathrm{~K}$, a band at $3650 \mathrm{~cm}^{-1}$ developed during the first minute of reaction and then decreased in intensity, while a new small band at $3635 \mathrm{~cm}^{-1}$ arose (Fig. 7A). It is worth noticing that the behavior of the $\mathrm{OH}$ band located at $3650 \mathrm{~cm}^{-1}$ is similar to that of $(\mathrm{I}) \mathrm{Ga}-\mathrm{H}$ species mentioned above (see Fig. 3) and can be associated with the formation of $\mathrm{OH}$ via reaction (1), Scheme 1. At $623 \mathrm{~K}$ (Fig. 7 B), only one band at $3645 \mathrm{~cm}^{-1}$ evolved with increasing time, following the same trend that the band of (II) $\mathrm{Ga}-\mathrm{H}$ groups (and that of the $3635 \mathrm{~cm}^{-1}$ signal at $523 \mathrm{~K}$ ). On pure reduced ceria, a band at $3635 \mathrm{~cm}^{-1}$ was assigned to bridging type II-B OH groups, which shifted to higher wavenumber $\left(3647 \mathrm{~cm}^{-1}\right)$ upon increasing the degree of $\mathrm{CeO}_{2}$ reduction $[19,44]$. That is, as in the case of the (II) $\mathrm{Ga}-\mathrm{H}$ species, the position of the $\mathrm{OH}$ band seems to be also modified by the number of oxygen vacancies in its surroundings.

So, even though an unambiguous assignment of the 3635$3645 \mathrm{~cm}^{-1}$ signal was difficult due to the strong, overlapping bands in this region, it seems reasonable to suggest that $\mathrm{OH}$ on (or near) the vicinity of the (II) $\mathrm{Ga}-\mathrm{H}$ species could be the best option, as indicated by reaction (4) of Scheme 1 , since their isothermal evolutions run parallel. Further proof for the complete assignment of the $\mathrm{OH}$ signals can be found in Supplementary Information.

\subsection{Mathematical modeling of the surface reduction of $\mathrm{Ce}-\mathrm{Ga}$ mixed oxides}

The reaction pathways of $\mathrm{H}_{2}$ over $\mathrm{Ce}-\mathrm{Ga}$ mixed oxides proposed in Scheme 1 accounts for the main qualitative infrared experimental observations.
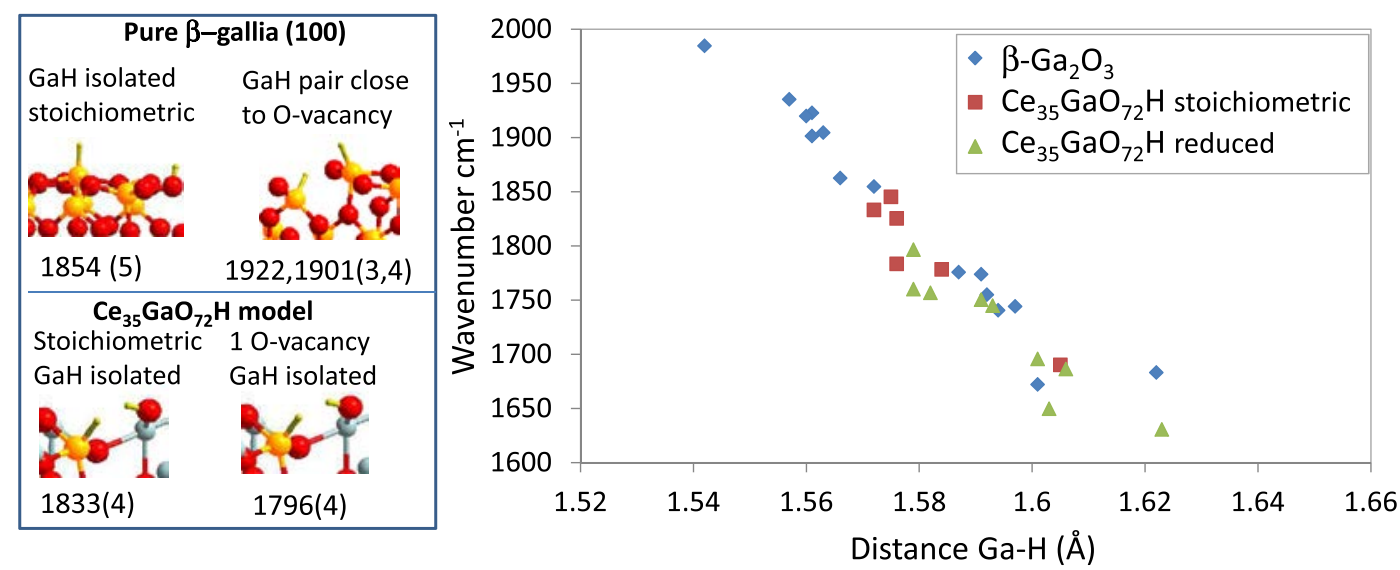

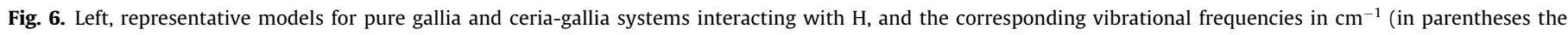
coordination of the gallium site). Right, plot of the computed vibrational frequencies vs. the Ga-H distance for a set of model systems. 


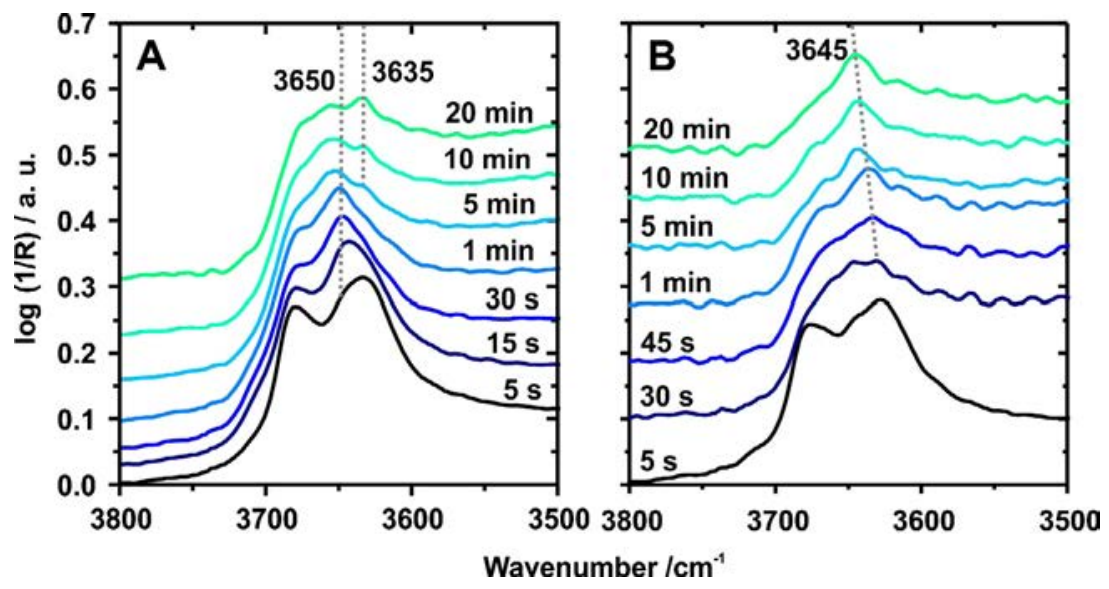

Fig. 7. $\mathrm{OH}$ stretching region of the DRIFT spectra recorded during the isothermal reduction with $\mathrm{H}_{2}$ at 523 (A) and $623 \mathrm{~K}$ (B) over Ce80Ga20.

Reaction (3) considers a direct source of $\mathrm{Ce}^{3+}$ formation in addition to that of reaction (2), where two $\mathrm{Ce}^{4+}$ cations react with $\mathrm{H}_{2}$ and surface oxygen anions to produce two $\mathrm{Ce}^{3+}$, water and an oxygen vacancy. The inclusion of this parallel reaction was necessary for two reasons: (i) because we cannot rule out the direct reduction -i.e., unpromoted by gallium cations- of $\mathrm{Ce}^{4+}$, since $\mathrm{Ce}^{3+}$ from different origins cannot be distinguished by IR (reactions (2) or (3)), and (ii) to model appropriately the quantitative evolution of the $\mathrm{Ce}^{3+}$ IR signal at the different tested temperatures. In fact, a model without taking into account this reaction failed to predict the behavior observed at $623 \mathrm{~K}$. Furthermore, a reaction considering the reduction of $\mathrm{Ce}^{4+}$ by (II) $\mathrm{Ga}-\mathrm{H}$ species was also tested, but its contribution to the overall concentration of $\mathrm{Ce}^{3+}$ was negligible; that is, it did not contribute significantly to a better fitting of the model.

To duly take into account the evolution with time of the surface reduction process of the mixed oxides upon introducing the $\mathrm{H}_{2}$ stream, it must be recalled that the DRIFT cell behaves like a continuous stirred tank reactor (CSTR) and, so, the inclusion of the residence time of the cell in the model equations is unavoidable. Nonetheless, as the experiments were performed under pure $\mathrm{H}_{2}$ flow, its consumption by the reactions with the solid phase could be neglected because it was always present in large excess.

So, the model equations derived for the IR-observable species followed by DRIFT are the following:

$$
\begin{aligned}
& \frac{d \Gamma_{(\mathrm{I}) \mathrm{Ga}-\mathrm{H}}}{d t}=k_{1} \cdot \Gamma_{(\mathrm{I}) \mathrm{Ga}} \cdot p_{\mathrm{H} 2}-k_{2} \cdot \Gamma_{(\mathrm{I}) \mathrm{Ga}-\mathrm{H}} \cdot \Gamma_{\mathrm{Ce}^{4+}}^{2} \\
& \frac{d \Gamma_{\mathrm{Ce}^{3+}}}{d t}=2 \cdot k_{2} \cdot \Gamma_{(\mathrm{I}) \mathrm{Ga}-\mathrm{H}} \cdot \Gamma_{\mathrm{Ce}^{4+}}^{2}+2 \cdot k_{3} \cdot \Gamma_{\mathrm{Ce}^{4+}}^{2} \cdot \Gamma_{\mathrm{O}^{2-}} \cdot p_{\mathrm{H} 2} \\
& \frac{d \Gamma_{(\mathrm{II}) \mathrm{Ga}-\mathrm{H}}}{d t}=k_{4} \cdot \Gamma_{(\mathrm{II}) \mathrm{Ga}} \cdot p_{\mathrm{H} 2}^{2}
\end{aligned}
$$

$p_{\mathrm{H} 2}=p_{\mathrm{H} 2}^{e} \cdot\left(1-e^{-t / \tau}\right)$

where $\Gamma_{n}$ is the surface concentration of each $n$ species, expressed as sites or species per $\mathrm{nm}^{2}$ ( $n$ stands for the different surface sites or species involved in the reactions (1)-(4), that is, (I) $\mathrm{Ga}$, (I) $\mathrm{Ga}-\mathrm{H}$, (II) $\mathrm{Ga}$, (II) $\left.\mathrm{Ga}-\mathrm{H}, \mathrm{Ce}^{4+}, \mathrm{Ce}^{3+}, \mathrm{O}^{2-}\right), \tau$ is the residence time of the DRIFT cell, $p_{\mathrm{H} 2}^{e}$ is the inlet $\mathrm{H}_{2}$ pressure and $k_{i}$ (with $i=1-4$ reactions) are the kinetic rate constants of reactions (1)-(4).

DRIFT data can be expressed as a (pseudo-) absorbance, that is, $\log 1 / R$, where $R$ is the reflectance of the sample, or analyzed using the Kubelka-Munk (KM) function. However, it has been reported that the use of (pseudo-) absorbance gives a better linear representation of band intensity versus surface coverage than the KM func- tion in the relative reflectance range between $100 \%$ and $60 \%$ [45]. Thus, in our model equations the surface concentration of the species followed by IR was replaced by the (pseudo-) absorbance, by means of the Beer's law equation:

$A=\varepsilon \cdot b \cdot \Gamma=\varepsilon^{\prime} \cdot \Gamma$

where $A$ is the integrated absorbance, $\varepsilon$ is the absorptivity of the IRobservable species, $b$ is the optical path, and $\varepsilon^{\prime}=\varepsilon \cdot b$.

Considering the above and performing each mass balance, the resulting differential equations based on the IR-observable data were written as a function of the initial surface concentration $\left(\Gamma_{m}{ }^{0}\right.$, where $m$ stands for (I)Ga, $\mathrm{Ce}^{4+}$ or $\left.\mathrm{O}^{2-}\right)$, which are unknown, as well as the $\varepsilon_{p}{ }^{\prime}$ values (where $p$ stands for $\mathrm{Ga}-\mathrm{H}$ or $\mathrm{Ce}^{3+}$ ). See Supplementary Information.

To obtain directly the activation energy for each reaction, the kinetic rate constants were written using the Arrhenius equation, assuming a proportional ratio for the pre-exponential factors of reaction (1), (2) and (4) between Ce80Ga20 and Ce90Ga10 samples. To reduce the computational difficulties arising from the strong correlation between preexponential factors and activation energies, the model constants were reparameterized. The RungeKutta 4th order algorithm was used to solve the set of differential equations. All these features are fully detailed and justified in the Supplementary Information, as well as the procedures employed to reduce computational difficulty, to finally achieve the estimated parameters shown in Table 2. Model predictions for Ce80Ga20 and Ce90Ga10 are depicted as solid lines in Figs. 3 and 4, indicating excellent agreement.

\subsection{Surface species concentration predicted by the mathematical modeling}

Regarding the concentration estimated by the model, several features can be noticed. Firstly, the initial concentration of active $\mathrm{Ce}^{4+}$ cations $\left(\Gamma_{\mathrm{Ce}^{4+}}^{0}\right)$ in Ce80Ga20 almost doubled that of Ce90Ga10. This seemingly contradictory result, both from a strictly geometric viewpoint and/or considering the XPS data (see Table 1), strongly suggests that the model predictions are indicative of the amount of surface cerium cations effectively (i.e., kinetically) involved in the reduction process. Such amount increases with the $\mathrm{Ga}^{3+}$ content. Moreover, the model also predicts that the amount of surface oxygen anions involved in the direct reduction of $\mathrm{Ce}^{4+}$ (that is step 3, without any promotion of the gallium ions), becomes higher in Ce80Ga20. To test whether this model prediction was an artifact, additional computer runs were done, in which single values of the initial surface concentrations of cerium cations 
Table 2

Parameter values estimated by the 4-step reduction model (modeling stage 4 - see Supplementary Information).

\begin{tabular}{|c|c|c|c|c|c|c|}
\hline \multirow[t]{2}{*}{ Parameter $^{\mathrm{a}}$} & \multicolumn{3}{|l|}{ Ce90Ga10 } & \multicolumn{3}{|l|}{ Ce80Ga20 } \\
\hline & Mean value & Lower limit $^{\mathrm{b}}$ & Upper limit $^{\mathrm{b}}$ & Mean value & Lower limit ${ }^{\mathrm{b}}$ & Upper limit \\
\hline$A_{1 j}$ & $2.88 \times 10^{2}$ & $6.65 \times 10^{1}$ & $1.86 \times 10^{4}$ & $1.80 \times 10^{3 c}$ & $4.14 \times 10^{2 c}$ & $1.16 \times 10^{5 c}$ \\
\hline $\mathrm{Ea}_{1 j}$ & 2.18 & 0.71 & 6.72 & 4.79 & 4.71 & 4.86 \\
\hline$A_{2 j}$ & $1.08 \times 10^{10}$ & $2.07 \times 10^{9}$ & $6.09 \times 10^{10}$ & $6.74 \times 10^{10 c}$ & $1.30 \times 10^{10 c}$ & $3.79 \times 10^{11 c}$ \\
\hline $\mathrm{Ea}_{2 j}$ & 22.14 & 20.77 & 23.61 & 24.55 & 24.42 & 24.68 \\
\hline$A_{3 j}$ & $3.70 \times 10^{8}$ & $9.40 \times 10^{7}$ & $1.53 \times 10^{9}$ & $1.90 \times 10^{7}$ & $1.61 \times 10^{7}$ & $2.24 \times 10^{7}$ \\
\hline $\mathrm{Ea}_{3 j}$ & 22.74 & 21.62 & 23.92 & 22.74 & 21.62 & 23.92 \\
\hline$A_{4 j}$ & 3.44 & 1.5 & 8.47 & $21.42^{\mathrm{c}}$ & $9.34^{\mathrm{C}}$ & $52.70^{c}$ \\
\hline $\mathrm{Ea}_{4 j}$ & 9.39 & 8.56 & 10.29 & 10.43 & 10.34 & 10.52 \\
\hline$\varepsilon_{\mathrm{Ga}-\mathrm{H}}^{\prime}$ & 109.1 & 94.0 & 124.2 & 109.1 & 94.0 & 124.2 \\
\hline$\varepsilon_{\mathrm{Ce}^{3+}}^{\prime}$ & 4.09 & - & - & 4.09 & - & - \\
\hline$\Gamma_{(\mathrm{I}) \mathrm{Ga}}^{0}$ & 0.10 & 0.09 & 0.11 & 0.15 & 0.13 & 0.16 \\
\hline$\Gamma_{\mathrm{Ce}^{4+}}^{0}$ & 0.97 & 0.81 & 1.14 & 1.84 & 1.77 & 1.92 \\
\hline$\Gamma_{\mathrm{O}^{2-}}^{0}$ & 0.35 & 0.27 & 0.42 & 1.00 & 0.83 & 1.18 \\
\hline$\beta$ & & & & 6.23 & 5.82 & 6.63 \\
\hline
\end{tabular}

$A_{1 j}[=] 1 /(\min$ atm $), A_{2 j}[=] \mathrm{m}^{4} /\left(\min \operatorname{site}^{2}\right), A_{3 j}[=] \mathrm{m}^{4} /\left(\min\right.$ atm site $\left.{ }^{2}\right)$ and $A_{4 j}[=] 1 /\left(\mathrm{min} \mathrm{atm}^{2}\right) ; \mathrm{Ea}_{i j}[=] \mathrm{kcal} / \mathrm{mol} ; \varepsilon_{n}[=] \mathrm{nm}{ }^{2} / \mathrm{site} ; \Gamma^{0}{ }_{n}[=] \mathrm{site} / \mathrm{nm}^{2}$.

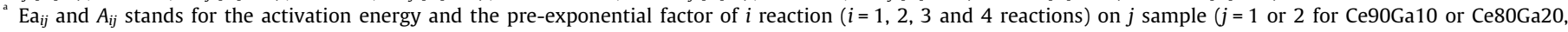
respectively).

'For a 95\% confidence interval.

Calculated as $A_{i 2}=A_{i 1} \times \beta(i=1,2$ and 4 reactions $)$.

$\left(\Gamma_{\mathrm{Ce}^{4+}}^{0}\right)$ and/or oxygen anions $\left(\Gamma_{\mathrm{O}^{2-}}^{0}\right)$ were used for both samples. In every case the model outputs were unable to represent the experimental results appropriately, which confirms once again the previous hypotheses.

In order to gain more information on the origin of $\mathrm{Ce}^{3+}$, the model was used to predict the contribution of steps 2 and 3 to the total surface concentration of those cations produced during the reduction of both samples (Fig. S13). First, it can be observed there that the formation of $\mathrm{Ce}^{3+}$ via step 2, is much faster than its formation from step 3 (these are labeled $\mathrm{Ce}^{3+} \mathrm{s} 2$ and $\mathrm{Ce}^{3+} \mathrm{s} 3$, respectively, in Fig. S13). In fact, the maximum concentration of $\mathrm{Ce}^{3+} \mathrm{s} 2$, whose production is promoted by the (I)Ga-H species, is already reached at the lowest temperature tested in this IR study and in less than $1 \mathrm{~min}$, regardless of the gallium loading. The maximum concentration of $\mathrm{Ce}^{3+} \mathrm{s} 2$ reached on Ce80Ga20 is 1.4 -fold higher than for Ce90Ga10, which agrees well with the ratio of the initial (I)Ga sites $\left(\Gamma_{(\mathrm{I}) \mathrm{Ga}}^{0}\right)$ of both materials, as expected. Second, the amount of $\mathrm{Ce}^{3+}$ produced via step 3 increases at higher temperature and continues to grow, slowly, even at $623 \mathrm{~K}$. The evolution of the $\mathrm{Ce}^{3+} \mathrm{s} 3$ infrared signal predicted by the model for longer periods of time for both samples is shown in Supplementary Information, Fig. S14. Interestingly, the predicted asymptotic value of $\mathrm{Ce}^{3+}$ that is reached via step 3 was approximately 2.2-fold higher for Ce80Ga20 than Ce90Ga10.

Other results coming from the time evolution of the surface species concentration that can be predicted or explained by our 4-step reaction mechanism are the following:

- The higher peak values of the integrated absorbance of the (I) Ga-H species (that is, $\Gamma_{(\mathrm{I}) \mathrm{Ga}-\mathrm{H}}$ ) on Ce90Ga10 in comparison with those on Ce80Ga20 at $523 \mathrm{~K}$ (shown in Figs. 3 and 4), on the basis of a higher reaction rate of step 2 $\left(r_{2}=k_{2} \cdot \Gamma_{(\mathrm{I}) \mathrm{Ga}-\mathrm{H}} \cdot \Gamma_{\mathrm{Ce}^{4+}}^{2}\right)$ with respect to the rate of step $1\left(r_{1}-\right.$ $\left.=k_{1} \cdot \Gamma_{(\mathrm{I}) \mathrm{Ga}} \cdot p_{\mathrm{H} 2}\right)$ on Ce80Ga20, which leads to a lower accumulation of (I) $\mathrm{Ga}-\mathrm{H}$ species, because they are consumed in step 2 .

- As soon as the concentration of $\mathrm{Ce}^{3+}$ begins to stabilize, the formation of (II)Ga-H species (step 4) starts (Figs. 3 and 4). Thereafter, for longer reduction times $(t \gg 20 \mathrm{~min}$, see Fig. S14) the concentration of the (II) $\mathrm{Ga}-\mathrm{H}$ species should reach a plateau on either sample, and the ratio of the maximum concentration of (II)Ga-H on Ce80Ga20 with respect to Ce90Ga10 should be identical to the ratio of initial (I)Ga sites, which is actually expected from the consistency of the proposed mechanism.

- Even though at this stage it is not possible to duly anticipate kinetic isotope effects over the evolutions of (I)Ga-D and $\mathrm{Ce}^{3+}$ species, as compared to their counterparts under $\mathrm{H}_{2}$ reduction, since the elementary steps involved in each reaction shown in Scheme 1 are not known, it was still possible to predict the evolution with time of the surface concentration of the indicated species upon $\mathrm{D}_{2}$ reduction of the ceria-gallia mixed oxides using the 4-steps model in combination with just spectral and literature data, as detailed in the Supplementary Information section.

\subsection{Mechanism of $\mathrm{H}_{2}$ dissociation and water elimination}

A reaction path involving first the $\mathrm{H}-\mathrm{H}$ bond break to form a $\mathrm{MH} / \mathrm{OH}$ (hydride/hydroxyl) pair, and then the recombination to form water was calculated with DFT for a ceria-gallia mixed oxide model (steps 1 and 2), the pure ceria (step 3) and -for comparisona pure gallia model. The energetic profiles obtained are depicted in Fig. 8 .

For the mixed ceria-gallia model the activation barriers are $0.20 \mathrm{eV}$ for step 1 , and $1.03 \mathrm{eV}$ for step 2 . The parameters obtained from the kinetic modeling were $\mathrm{Ea}_{1 j}=0.09 \mathrm{eV}$ and $0.21 \mathrm{eV}$ (step 1) and $\mathrm{Ea}_{2 j}=0.96 \mathrm{eV}$ and $1.07 \mathrm{eV}$ (step 2) for Ce90Ga10 and Ce80Ga20, respectively ( $1 \mathrm{eV}=23 \mathrm{kcal} / \mathrm{mol}$, see Table 2$)$.

The pure ceria model shows an activation barrier of $1.08 \mathrm{eV}$ for $\mathrm{H}_{2}$ dissociation and $0.25 \mathrm{eV}$ for water formation (TS2). At this point it is relevant to note that on this oxide:

(i) The mechanism proceeds via the formation of a $\mathrm{CeH} / \mathrm{OH}$ pair, which is unstable by $0.83 \mathrm{eV}$ (likely not seen by IR), followed by a low barrier recombination $(0.25 \mathrm{eV})$ to form water. The global barrier for the whole process is thus $1.08 \mathrm{eV}$.

(ii) The $\mathrm{CeH}$ intermediate has been reported in the literature $[24,46,47]$ as playing a role in the formation of $2 \mathrm{CeOH}$ groups, which is a very stable structure (around $2.5 \mathrm{eV}$ more stable than the reference). We calculated the energetic barrier to form water from two neighboring hydroxyl groups 

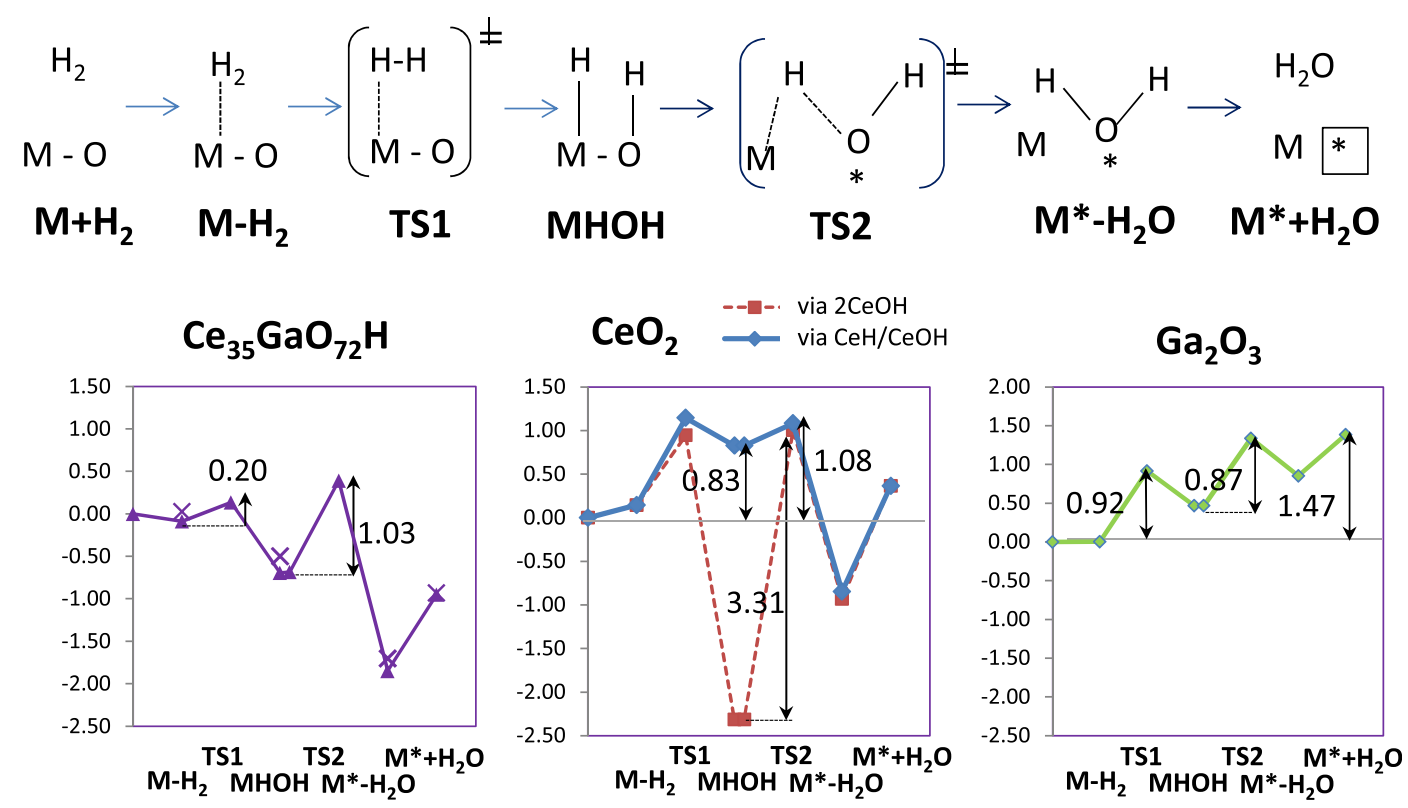

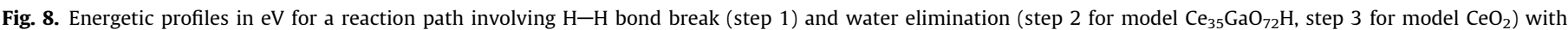

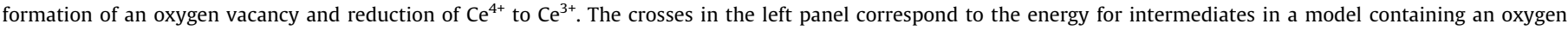
vacancy as in Fig. S2.

and found a value of $3.3 \mathrm{eV}$. The kinetic modeling gave an activation barrier $\mathrm{Ea}_{3}=0.98 \mathrm{eV}$, which supports the reaction through a $\mathrm{CeH}$ (unstable) intermediate rather than the $\mathrm{CeOH}$ (very stable) groups. Note that the IR observable signal was from $\mathrm{Ce}^{3+}$, which might arise either from a hydroxylated surface $\mathrm{Ce}^{3+}-\mathrm{OH}$ or from an oxygen vacancy formed upon desorption of water. The value of $\mathrm{Ea}_{3}=0.98 \mathrm{eV}$ accounts thus for the global reaction and is compatible with a two-step reduction via a $\mathrm{CeH} / \mathrm{CeOH}$ intermediate, but not involving a $\mathrm{CeOH} /$ $\mathrm{CeOH}$ intermediate.

For comparison, pure gallia show an uphill profile with activation energies of $\sim 0.9 \mathrm{eV}$ for each step, with a global endothermic energetic balance of $1.47 \mathrm{eV}$.

Oxygen vacancies may play a role in the reaction path. In order to explore the effect of the presence of oxygen vacancies, we have computed the energy of the intermediates involved in the mechanism of Fig. 8, for an isolated-Ga model with a vacancy (Fig. S2). The energies are marked with a cross on Fig. 8, left panel. The energy profile is destabilized by $\sim 10 \%$ for the reduced model compared to the stoichiometric one. However, the relative energies between two consecutive intermediates are maintained: $\mathrm{H}_{2}-\mathrm{MO}$ to $\mathrm{MHOH}$ involves $-0.60 \mathrm{eV}$ for the stoichiometric $(-0.53 \mathrm{eV}$ for the reduced), and $\mathrm{MHOH}$ to $\mathrm{M}^{*}+\mathrm{H}_{2} \mathrm{O}-1.15 \mathrm{eV}$ for the stoichiometric $(-1.20 \mathrm{eV}$ for the reduced) models. Also, the geometry of the intermediates only changes slightly in the presence of the vacancy. It is thus expected that the energy barriers are not significantly affected by the presence of a vacancy for the Ga-containing catalyst, at least at first stages.

To investigate further the role of vacancies in all the regions involved ( $\mathrm{Ce}-\mathrm{Ga}$ boundaries, pure $\mathrm{Ce}$ and pure $\mathrm{Ga}$ regions), we have computed the oxygen vacancy formation energy for the isolated and cluster models (see Supporting Information). The easiest vacancy to be formed corresponds to Ga...O-Ce sites ( $E_{\mathrm{vac}} 1.31 \mathrm{eV}$ isolated, $1.34 \mathrm{eV}$ cluster model). At a second stage the vacancies would be formed in pure ceria regions ( $E_{\mathrm{vac}} 2.35 \mathrm{eV}$ isolated, $1.93 \mathrm{eV}$ cluster model), which is consistent with the mechanism proposed (step 3 ). After high reduction, vacancies would be formed on pure gallia regions (step 4) with $E_{\mathrm{vac}} 4.41 \mathrm{eV}$. As regards the energetic barriers, the rate limiting step being the heterolytic dissociation of $\mathrm{H}_{2}$ on $\mathrm{Ga}$...O-Ce sites, the value is not expected to be affected by the presence of vacancies. Instead, a decrease in the number of dissociation sites is expected upon formation of vacancies, since surface $\mathrm{O}$ sites are needed to form $\mathrm{MH} / \mathrm{OH}$ pairs. This would induce a change in the mechanism involving $\mathrm{Ce}-\mathrm{O}-\mathrm{Ce}$ sites (step 3), or $\mathrm{Ga}-\mathrm{O}-\mathrm{Ga}$ sites (sites $\mathrm{Ga}(\mathrm{II}) \mathrm{H}$ in step 4).

In regard to the values of the apparent activation energies for reactions ( 1 ), (2) and (4) found by the kinetic model, they were statistically equivalent for both materials (Table 2 ). The activation energy for reaction (3) was adjusted as a single parameter for both gallia-ceria mixed oxides $\left(\mathrm{Ea}_{31}=\mathrm{Ea}_{32}\right)$, as detailed in the Supplementary Information.

Interestingly, it can also be noted that the activation energies for the reactions involving the reduction of $\mathrm{Ce}^{4+}$, with or without intervention of neighboring gallium cations (reactions (2) and (3)) are practically the same $(22-25 \mathrm{kcal} / \mathrm{mol})$. However, the corresponding pre-exponential factors differ substantially, the one for reaction (2) being about two orders of magnitude higher, which suggests significant activation entropy differences between these two reactions.

Of course, the easier breakage of the $\mathrm{H}-\mathrm{H}$ bond might imply a higher global reaction rate at lower temperatures as long as such cleavage was involved in the rate determining step $(r d s)$. That seems to be the case of alkyne hydrogenation, where the gallium addition to ceria has proved to boost the activity or pure ceria [9]. However, the still low turnover frequency achieved for acetylene and methylacetylene hydrogenation on these oxides, as compared to the technological, modified Pd-based catalysts used for alkynes hydrogenation, can be interpreted as a shifting of the $r d s$ to an active surface site that still demands a performance enhancement.

It must be kept in mind, also, that the increase of temperature (and/or of gallium loading) favors the formation of oxygen vacancies and, then, (I)Ga sites become converted into (II)Ga sites. However, these last sites are not as efficient as the first ones for $\mathrm{H}_{2}$ dissociation, since the kinetic constant for reaction (4) is approx. $10^{4}$-fold lower than that of reaction $(1)\left(k_{4 j} \ll k_{1 j}\right)$. So, the hydrogenation capability of the $\mathrm{Ce}-\mathrm{Ga}$ mixed oxides would drop at 
higher temperatures or gallium content. This is another, more precise interpretation for the reaction rate decrease of alkynes hydrogenation than that given by some of us in previous work [9], in which we assumed an (unspecified) loss of active sites.

\subsection{Surface structure}

The NMR results in Section 3.2 suggest the presence of $\mathrm{Ga}_{2} \mathrm{O}_{3}$ nanodomains. We postulate that the active sites for $\mathrm{H}_{2}$ dissociation (step 1) are located in the boundary of these nanodomains, in close vicinity of cerium centers. This is supported by our kinetic analysis. The initial surface concentrations of (I)Ga sites $\left[\Gamma_{(\mathrm{I}) \mathrm{Ga}}^{0} /\left(\Gamma_{\mathrm{Ce}^{4+}}^{0}+\Gamma_{(\mathrm{I}) \mathrm{Ga}}^{0}\right)\right]$ predicted by the mathematical modeling for Ce90Ga10 were close to the surface concentration ratio measured by XPS [0.09 (Table 2) vs. 0.10 (Table 1), respectively]. However, for Ce80Ga20 the $\left[\Gamma_{(\mathrm{I}) \mathrm{Ga}}^{0} /\left(\Gamma_{\mathrm{Ce}^{4+}}^{0}+\Gamma_{(\mathrm{I}) \mathrm{Ga}}^{0}\right)\right]$ ratio given by the model was about $\sim 3$-fold lower than that measured by XPS [0.07 (Table 2) vs. 0.19 (Table 1), respectively], which suggests that not all the gallium cations present in the surface of -at least- Ce80Ga20 are type (I)Ga active sites that participate (kinetically) in the reduction mechanism or that, in other words, the impact of doubling the amount of $\mathrm{Ga}$ in the ceria-gallia mixed oxide does not imply a direct proportionality with its atomic loading in the reaction in which such species are involved, but rather (most likely) with the perimeter of the gallia nanodomains instead. In line with this finding, the ratio of the $\Gamma_{(\mathrm{I}) \mathrm{Ga}}^{0}$ values between Ce80Ga20 and Ce90Ga10 estimated by the kinetic model, equal to 1.5 , indicates that not each of the surface gallium cations is participating in step 1, since the XPS ratio for surface gallium concentration is 2-fold higher for Ce80Ga20 than for Ce90Ga10. That is, the increase of the gallium loading, which is truly reflected as an increase of the surface concentration, could be also related to the surface clustering of gallium cations where the "active" oxygen atoms for the dissociation of the hydrogen molecule are encircling gallia nanopatches. In other words, the active sites for $\mathrm{H}_{2}$ dissociation may well reside in the perimeter or boundary of surface gallia clusters, which is indicated by dotted lines between $\mathrm{Ga}^{3+}$ and $\mathrm{O}$ in the conformation of the type I Ga site (Scheme 1, blue sites in Fig. 1). The affinity of gallium to aggregate forming pairs has been reported by some of us for bulk ceria-gallia [22] and seems to be confirmed also for surfaces, and has motivated the study of the clusterGa model shown in Fig. 1. The analysis of the structure of this model shows that the local environment of the Ga $\ldots$ O sites is very similar to that of the isolated model; thus, increasing the content in gallia would not affect the activation barriers. However, the presence of gallia nanodomains decreases the number of Ga $\cdots O$ active sites: there are 2 sites/Ga in the isolated Ga model, and 4 sites/7 Ga in the cluster model, see Fig. 1.

\subsection{Implications for catalytic processes}

Probably, one of the most important statements that can be derived from our study of the reaction pathways for the reduction of gallia-ceria mixed oxides is related to the following, and plausible strong catalytic connotations: Gallia nanoclusters formed on the $\mathrm{CeO}_{2}$ matrix are able to generate very active sites in their perimeter (that is, the Ga...O-Ce interface), which decrease the activation barrier for $\mathrm{H}_{2}$ dissociation, making the $\mathrm{Ce}-\mathrm{Ga}$ mixed oxides very attractive materials -without the need of, i.e., costly noble metals- for the formulation of novel hydrogenation catalysts.

There are several properties that might be explored for the application of these mixed oxides in specific catalytic reactions. The first one is their enhanced reducibility, which might favor the oxygen storage capacity of the materials and then, oxidation processes [49-53]. The second one is the efficient decrease of the
$\mathrm{H}_{2}$ bond breakage activation energy, which is interesting in reactions where the scission of the $\mathrm{H}_{2}$ molecule is the rate-limiting step, like for the selective hydrogenation of acetylenic compounds [9]. In this case, however, the formation of too many oxygen vacancies depletes the amount of active sites and is therefore detrimental for the activity. The extent of reduction and the number of active sites could then be tuned by modifying the gallium content.

Finally, gallium-modified zeolites have been used from decades in the reaction of dehydrogenation/aromatization of light alkanes $[4,48]$. It has been proposed that the rate determining step of those reaction is the cleavage of the $\mathrm{C}-\mathrm{H}$ bond, which can take place over isolated gallium hydride or dinuclear gallium species. From the above presented experimental results it is possible to think that the tuning of $\mathrm{Ga}$ /zeolites catalysts with the addition of cerium could favor the formation of the Ga-alkyl intermediate where balance amounts of $\mathrm{Ce}-\mathrm{O}-\mathrm{Ga}$ sites might have a significant impact on catalytic performances.

\section{Conclusions}

We propose a mechanism for $\mathrm{H}_{2}$ dissociation and subsequent water elimination in ceria and gallium-promoted ceria catalysts. On the ceria-gallia mixed oxides interface gallium sites break the $\mathrm{H}-\mathrm{H}$ bond forming $\mathrm{GaH}$ and $\mathrm{OH}$ surface sites, that recombine to form water and an oxygen vacancy that reduce $\mathrm{Ce}^{4+}$ to $\mathrm{Ce}^{3+}$. Our proposed mechanism finely shows that: (i) the reduction of surface $\mathrm{Ce}^{4+}$ is faster on the gallium-promoted ceria than on pure $\mathrm{CeO}_{2}$, (ii) the higher the gallium loading is, the higher the amount of surface oxygen vacancies, (iii) the active sites for $\mathrm{H}_{2}$ activation are located at the interface between gallia-rich and ceria-rich (nano)domains, and (iv) refined modeling including gallia nanocluster supports the fact that the nature of the Ga. . O sites is very similar to the isolated ones, and thus, the reaction barrier should also be similar and independent of the gallia content.

Our conclusions may have important catalytic impact in the search of novel oxide materials, other than (expensive) noble metals, active in hydrogenation/dehydrogenation reactions.

\section{Acknowledgment}

The financial support from Universidad Nacional del Litoral (CAID 2011, PI PI 501201101 00311), ANPCyT (PICT-2012-1280 and PICT-2014-0497) and CONICET (PIP-2014-086) is acknowledged. This work was performed using HPC resources from GENCI-CINES/IDRIS (Grant 2015-x2015082131, 2016x2016082131) and the CCRE-DSI of Université P. M. Curie. MC is grateful to Dr. B. Diawara for the Modelview visualization program and Dr. F. Tielens for fruitful discussions. The French Région Ile de France - SESAME program is acknowledged for financial support (700 MHz spectrometer). The COST Action CM 1104 is also acknowledged.

\section{Appendix A. Supplementary material}

Supplementary data associated with this article can be found, in the online version, at http://dx.doi.org/10.1016/j.jcat.2016.11.029.

\section{References}

[1] G. Ertl, H. Knözinger, J. Weitkamp (Eds.), Handbook of Heterogeneous Catalysis, vol. 1, Wiley-VCH, France, 1997, pp. 13-17.

[2] C. Copéret, D.P. Estes, K. Larmier, K. Searles, Chem. Rev. 116 (2016) 8463-8505.

[3] Y. Ono, Catal. Rev.: Sci. Eng. 34 (1992) 179-226.

[4] J.J.H.B. Sattler, J. Ruiz-Martínez, E. Santillán-Jiménez, B.M. Weckhuysen, Chem. Rev. 114 (2014) 10613-10653.

[5] D. Chiavassa, S.E. Collins, A.L. Bonivardi, M.A. Baltanás, Chem. Eng. J. 150 (2009) 204-212. 
[6] S.E. Collins, M.A. Baltanás, A.L. Bonivardi, J. Catal. 226 (2004) 410-421.

[7] S.E. Collins, J.J. Delgado, C. Mira, J.J. Calvino, S. Bernal, D.L. Chiavassa, M.A Baltanás, A.L. Bonivardi, J. Catal. 292 (2012) 90-98.

[8] S.E. Collins, M.A. Baltanás, A.L. Bonivardi, Langmuir 21 (2005) 962-970.

[9] G. Vilé, P. Dähler, J. Vecchietti, M. Baltanás, S. Collins, M. Calatayud, A. Bonivardi, J.J. Pérez-Ramírez, J. Catal. 324 (2015) 69-78.

[10] J. El Fallah, S. Boujana, H. Dexpert, A. Kiennemann, J. Majerus, O. Touret, F. Villain, F. Le Normand, J. Phys. Chem. 98 (1994) 5522-5533.

[11] F. Giordano, A. Trovarelli, C. de Leitenburg, M. Giona, J. Catal. 193 (2000) $273-$ 282.

[12] S. Schimming, G.S. Foo, O.D. LaMont, A.K. rogers, M.M. Yung, A.D. D’Amico, C. Sievers, J. Catal. 329 (2015) 335-347.

[13] J. Vecchietti, S. Collins, J.J. Delgado, M. Małecka, E. del Río, X. Chen, S. Bernal, A. Bonivardi, Top. Catal. 54 (2011) 201-209.

[14] J. Vecchietti, S. Collins, W. Xu, L. Barrio, D. Stacchiola, M. Calatayud, F. Tielens, J. J. Delgado, A. Bonivardi, J. Phys. Chem. C 117 (2013) 8822-8831.

[15] G. Finos, S. Collins, G. Blanco, E. del Rio, J.M. Cíes, S. Bernal, A. Bonivardi, Catal Today 180 (2012) 9-18.

[16] P. Meriaudeau, M. Primet, J. Mol. Catal. 61 (1990) 227-234.

[17] W. Jochum, S. Penner, K. Fottinger, R. Kramer, U. Rupprechter, B. Klotzer, J. Catal. 256 (2008) 268-277.

[18] C. Binet, A. Badri, J.C. Lavalley, J. Phys. Chem. 98 (1994) 6392-6398.

[19] C. Binet, M. Daturi, J.C. Lavalley, Catal. Today 50 (1999) 207-225.

[20] T. Tabakova, F. Boccuzzi, M. Manzoli, D. Andreeva, Appl. Catal. A: Gen. 252 (2003) 385-397.

[21] F.C. Meunier, D. Tibiletti, A. Goguet, D. Reid, R. Burch, Appl. Catal. A: Gen. 289 (2005) 104-112.

[22] P. Quaino, O. Syzgantseva, L. Siffert, F. Tielens, C. Minot, M. Calatayud, Chem. Phys. Lett. 519-520 (2012) 69-72.

[23] J. Carrasco, G. Vilé, D. Fernández-Torre, R. Pérez, J. Pérez-Ramírez, M.V. Ganduglia-Pirovano, J. Phys. Chem. C 118 (2014) 5352-5360.

[24] M. García-Melchor, N. López, J. Phys. Chem. C 118 (2014) 10921-10926.

[25] F.R. Negreiros, M.F. Camellone, S. Fabris, J. Phys. Chem. C 19 (2015) 21567 21573.

[26] S. Collins, G. Finos, R. Alcántara, E. del Río, S. Bernal, A. Bonivardi, Appl. Catal A: Gen. 388 (2010) 202-210.

[27] J.P. Holgado, R. Alvarez, G. Munuera, Appl. Surf. Sci. 161 (2000) 301-315.

[28] Dr. M. Mohai, Hungarian Academy of Sciences.

[29] M. Mohai, I. Bertóti, Correction for surface contaminations in XPS: a practical approach, in: H.J. Mathieu, B. Reihl, D. Briggs (Eds.), ECASIA 95, John Wiley \& Sons, Chichester, p. 675.

[30] D. Massiot, F. Fayon, M. Capron, I. King, S. Le Calvé, B. Alonso, J.-O. Durand, B. Bujoli, Z. Gan, G. Hoatson, Magn. Res. Chem. 20 (2002) 70-76.
[31] (a) J.P. Perdew, K. Burke, M. Ernzerhof, Phys. Rev. Lett. 77 (1996) 3865-3868;

b) J.P. Perdew, K. Burke, M. Ernzerhof, Phys. Rev. Lett. 78 (1997) 1396.

[32] (a) G. Kresse, J. Hafner, Phys. Rev. 47 (1993) 558-561;

(b) G. Kresse, J. Hafner, Phys. Rev. B 49 (1994) 14251-14269.

[33] (a) P.E. Blöchl, Phys. Rev. B 50 (1994) 17953-17979;

(b) G. Kresse, D. Joubert, Phys. Rev. B 59 (1999) 1758-1775.

[34] S.L. Dudarev, G.A. Botton, S.Y. Savrasov, C.J. Humphreys, A.P. Sutton, Phys. Rev, B 57 (1998) 1505-1509.

[35] G. Henkelman, B.P. Uberuaga, H. Jónsson, J. Chem. Phys. 113 (2000) 99019904.

[36] R. Carli, C.L. Bianchi, Appl. Surf. Sci. 74 (1994) 99-102.

[37] D. Massiot, I. Farnan, N. Gautier, D. Trumeau, A. Trokiner, J.P. Coutures, Solid State NMR 4 (1995) 241-248.

[38] C. Otero Areán, M. Rodríguez Delgado, V. Montouillout, D.Z. Massiot, Anorg. Allg. Chem. 631 (2005) 2121-2126.

[39] S.E. Collins, M.A. Baltanás, J.L. García-Fierro, A.L. Bonivardi, J. Catal. 211 (2002) 252-264.

[40] M. Calatayud, S. Collins, M. Baltanás, A. Bonivardi, Phys. Chem. Chem. Phys. 11 (2009) 1397-1405

[41] A.M. Ferrari, G. Pacchioni, J. Phys. Chem. 99 (1995) 17010-17018.

[42] M. Calatayud, A. Markovits, M. Ménétrey, B. Mguig, C. Minot, Catal. Today 85 (2003) 125-143.

[43] O.A. Syzgantseva, M. Calatayud, C. Minot, J. Phys. Chem. C 116 (2012) 66366644.

[44] A. Badri, C. Binet, J.C. Lavalley, J. Chem. Soc., Faraday Trans. 92 (1996) 46694673.

[45] J. Sirita, S. Phanichphant, F.C. Meunier, Anal. Chem. 79 (2007) 3912-3918.

[46] D. Fernández-Torrel, J. Carrasco, V. Ganduglia-Pirovano, R.J. Pérez, J. Chem. Phys. 141 (2014) 014703-014709.

[47] F.R. Negreiros, M. Farnesi Camellone, S. Fabris, J. Phys. Chem. C 119 (2015) 21567-21573.

[48] C. Copéret, Chem. Rev. 110 (2010) 656-680.

[49] F. Yang, J. Graciani, J. Evans, P. Liu, J. Hrbek, J.F. Sanz, J.A. Rodríguez, J. Am. Chem. Soc. 133 (2011) 3444-3451.

[50] D.Y. Wang, Y.J. Kang, V. Doan-Nguyen, J. Chen, R. Kungas, N.L. Wieder, K. Bakhmutsky, R.J. Gorte, C.B. Murray, Angew. Chem., Int. Ed. 50 (2011) 43784381.

[51] E. Aneggi, D. Wiater, C. de Leitenburg, J. Llorca, A. Trovarelli, ACS Catal. 4 (2014) $172-181$.

[52] J.A. Rodríguez, S. Ma, P. Liu, J. Hrbek, J. Evans, M. Pérez, Science 318 (2007) 1757-1760.

[53] J. Graciani, K. Mudiyanselage, F. Xu, A.E. Baber, J. Evans, S.D. Senanayake, D.J. Stacchiola, P. Liu, J. Hrbek, J. Fernández Sanz, J.A. Rodríguez, Science 345 (2014) 546-550. 